\title{
Integration of Computer- Aided Design and Finite Element Analysis Tools in a Small Manufacturing Enterprise
}

\author{
Joseph P. Elm \\ John E. Robert
}

June 2003

TECHNICAL REPORT

CMU/SEI-2003-TR-015

ESC-TR-2003-015 



\section{Integration of Computer-Aided Design and Finite Element Analysis Tools in a Small Manufacturing Enterprise}

CMU/SEI-2003-TR-015

ESC-TR-2003-015

Joseph P. Elm

John E. Robert

June 2003

Technology Insertion, Demonstration, and Evaluation (TIDE) Program 
This report was prepared for the

SEI Joint Program Office

HQ ESC/DIB

5 Eglin Street

Hanscom AFB, MA 01731-2116

The ideas and findings in this report should not be construed as an official DoD position. It is published in the interest of scientific and technical information exchange.

\section{FOR THE COMMANDER}

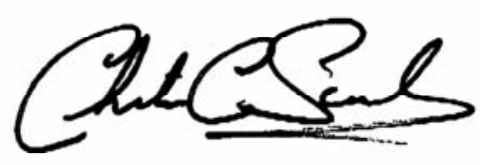

Christos Scondras

Chief of Programs, XPK

This work is sponsored by the U.S. Department of Defense. The Software Engineering Institute is a federally funded research and development center sponsored by the U.S. Department of Defense.

Copyright 2003 by Carnegie Mellon University.

\section{NO WARRANTY}

THIS CARNEGIE MELLON UNIVERSITY AND SOFTWARE ENGINEERING INSTITUTE MATERIAL IS FURNISHED ON AN "AS-IS" BASIS. CARNEGIE MELLON UNIVERSITY MAKES NO WARRANTIES OF ANY KIND, EITHER EXPRESSED OR IMPLIED, AS TO ANY MATTER INCLUDING, BUT NOT LIMITED TO, WARRANTY OF FITNESS FOR PURPOSE OR MERCHANTABILITY, EXCLUSIVITY, OR RESULTS OBTAINED FROM USE OF THE MATERIAL. CARNEGIE MELLON UNIVERSITY DOES NOT MAKE ANY WARRANTY OF ANY KIND WITH RESPECT TO FREEDOM FROM PATENT, TRADEMARK, OR COPYRIGHT INFRINGEMENT.

Use of any trademarks in this report is not intended in any way to infringe on the rights of the trademark holder.

Internal use. Permission to reproduce this document and to prepare derivative works from this document for internal use is granted, provided the copyright and "No Warranty" statements are included with all reproductions and derivative works.

External use. Requests for permission to reproduce this document or prepare derivative works of this document for external and commercial use should be addressed to the SEI Licensing Agent.

This work was created in the performance of Federal Government Contract Number F19628-00-C-0003 with Carnegie Mellon University for the operation of the Software Engineering Institute, a federally funded research and development center. The Government of the United States has a royalty-free government-purpose license to use, duplicate, or disclose the work, in whole or in part and in any manner, and to have or permit others to do so, for government purposes pursuant to the copyright license under the clause at 252.227-7013.

For information about purchasing paper copies of SEI reports, please visit the publications portion of our Web site (http://www.sei.cmu.edu/publications/pubweb.html). 


\section{Table of Contents}

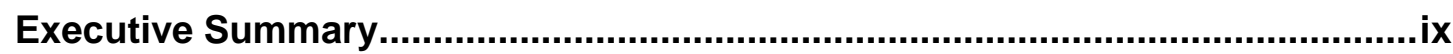

Abstract

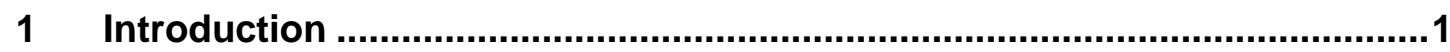

1.1 Small Manufacturing Enterprises and Technology Adoption......................1

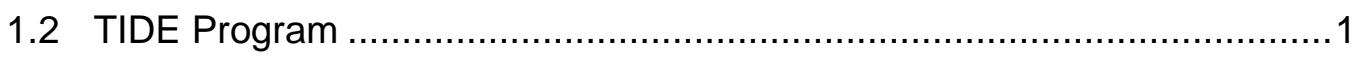

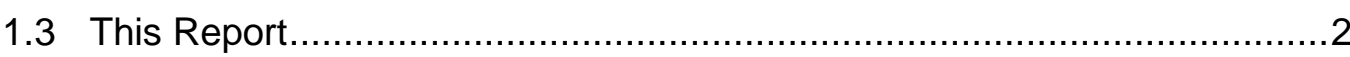

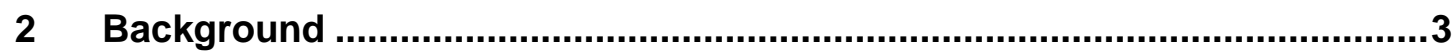

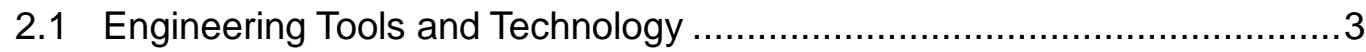

2.1.1 Computer-Aided Design (CAD) Functions...................................

2.1.2 Finite Element Analysis (FEA) Functions ………......................... 3

2.2 SME Environment ..................................................................... 4

2.2.1 SME Design Environment and Processes.....................................

2.2.2 SME Engineering Tool History ………………………….......

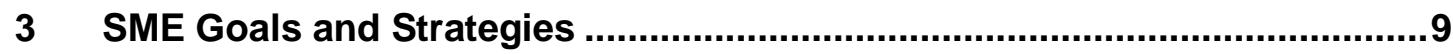

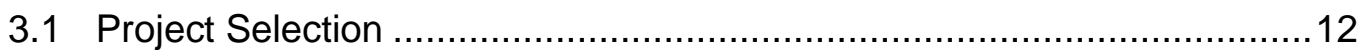

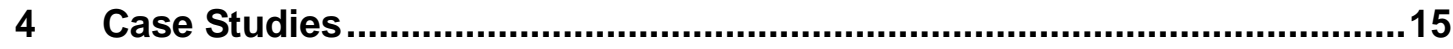

4.1 Case Study \#1 - Introduction of 3D CAD .......................................... 15

4.1.1 The Project ..................................................................... 15

4.1.2 Conceptual Design.............................................................15

4.1.3 Introduction of 3D CAD ..........................................................16

4.1.4 Product Design with an Integrated Product Model.......................17

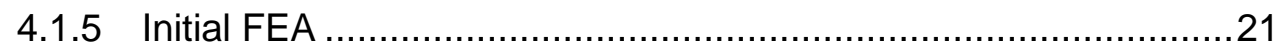

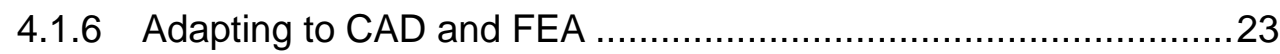

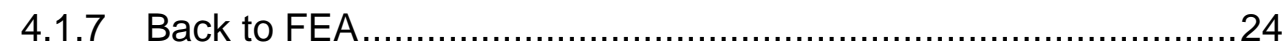

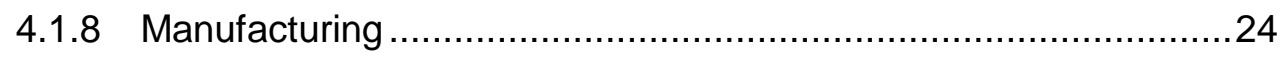

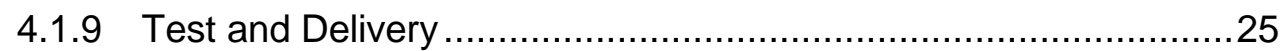

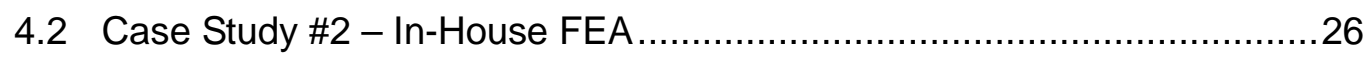

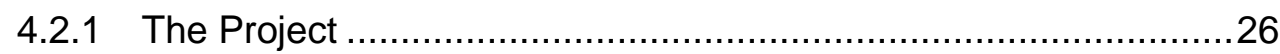

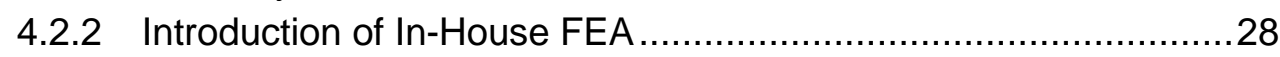

4.2.3 Conceptual Design and Analysis...............................................29 
4.2.4 Preliminary Design ..................................................... 31

4.2.5 Final Design ................................................................... 32

4.2.6 Manufacturing, Test and Delivery ........................................... 33

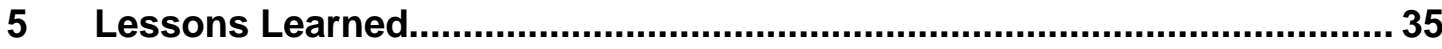

5.1 Design Process Lessons.............................................................. 35

5.1.1 FEA for Design Optimization ............................................. 35

5.1.2 Model Generation Using CAD ........................................... 36

5.2 3D CAD Lessons ....................................................................... 36

5.2.1 Integrated Model .......................................................... 36

5.2.2 Large Assembly Management .............................................. 37

5.2 .3 Structure Model to Suit FEA Needs ....................................... 37

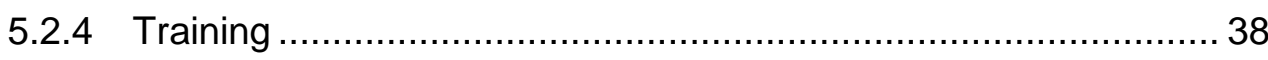

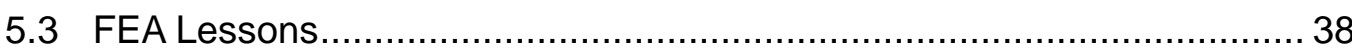

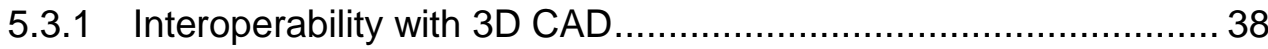

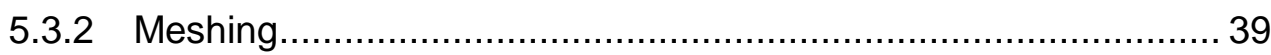

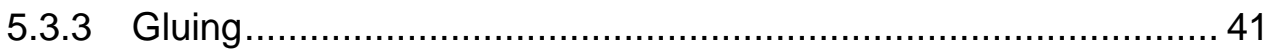

5.3.4 Ease of Use................................................................. 42

5.3.5 Training and Consulting Support ..................................... 42

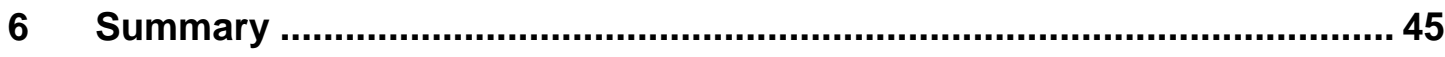

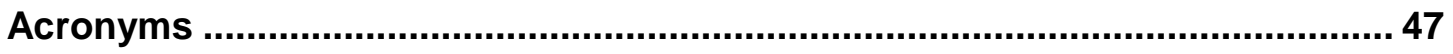

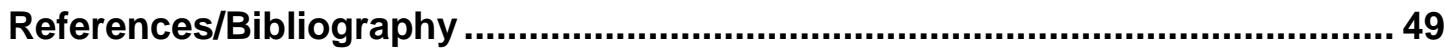




\section{List of Figures}

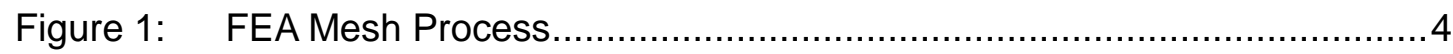

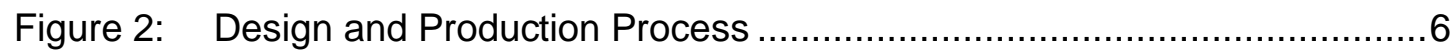

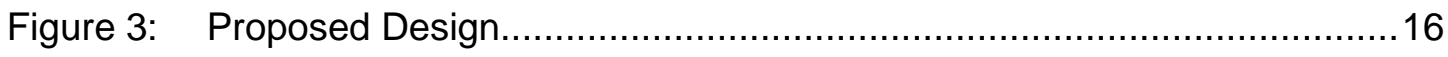

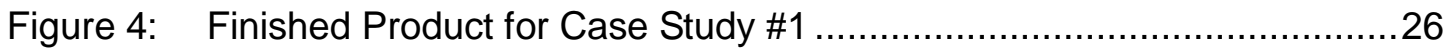

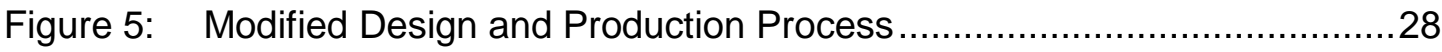

Figure 6: Conceptual Design from Study Contract...................................... 31

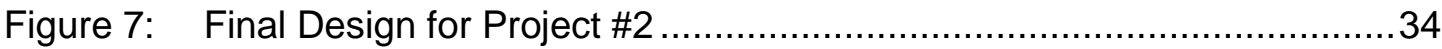

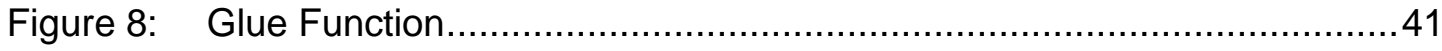


CMU/SEI-2003-TR-015 


\section{List of Tables}

Table 1: $\quad$ Mesh tradeoff example............................................................. 40 


\section{Acknowledgements}

The authors wish to thank Congressman Mike Doyle (D-14-PA), who was instrumental in establishing the TIDE program, and Carco Electronics, Mallet Technology, and Kingsway Engineering for their support and assistance in this research. 


\section{Executive Summary}

A small manufacturing enterprise (SME) providing custom-designed, precision, electromechanical equipment to the aerospace industry was faced with increasing competition in a stable market. Maintaining market share required this SME to provide faster deliveries, lower prices, and enhanced product performance. This SME initiated a program to adopt advanced computer-aided design (CAD) and computer-aided engineering (CAE) tools to improve their design and engineering capability and achieve these business goals.

This paper presents two case studies focusing on this SME's efforts to integrate threedimensional (3D) CAD and finite element analysis (FEA) into the design and engineering process. In doing this, the SME obtained additional benefits by revising the overall design process to include more analytical efforts at the early stages of the product design, thereby evolving from an "analysis for validation" to an "analysis for optimization" operational model. The insertion of the analysis effort into the design process is facilitated by the ability of advanced CAD tools to produce 3D representations of the product design, and by the ability of the FEA tool to accept product design information from the CAD tool.

During the first case study, the SME transitioned from a familiar two-dimensional (2D) CAD tool to a new 3D CAD tool. When using the 2D CAD tool, the SME created detailed design drawings for each component of the product. Interfaces between these components were verified manually. With the 3D CAD tool, the SME created a single integrated model of all components and individual component production drawings were derived from this integrated model. The integrated model provided automated verification of component interfaces, enabling the SME to identify and correct design errors (e.g., mismatched mating dimensions, mismatched bolt holes) during the design phase, rather than after the components were manufactured.

The SME addressed several challenges encountered during the creation and use of the integrated model. Due to the complexity of the product, the integrated model became quite large as the design progressed, creating difficulties in loading, updating, and storing the model. The SME developed a number of strategies to manage the size of the model. These strategies resulted in specific procedures defining effective ways to synthesize, organize, and utilize design data within the CAD tool.

During the second case study, the SME acquired in-house FEA capability to replace efforts that had previously been outsourced. The starting point of FEA is the creation of a 3D model 
of the product to be analyzed. The availability of a 3D model from the CAD tool offered the opportunity for the SME to transfer this model to the FEA tool. Although the FEA and CAD tools shared several common interface standards, the transfer of a 3D model from the CAD to the FEA tool was not without difficulty. In general, the CAD model contains considerably more detail than is required by the FEA tool. Attempting to analyze the detailed CAD model overtaxed the FEA tool, and yielded no results. The SME developed strategies to improve model transfer from CAD to FEA. These strategies resulted in procedures defining preferred methods of synthesizing and organizing the model. These methods enabled the SME to develop CAD models that were highly compatible with the FEA tool. They also enabled the SME to easily and temporarily remove detail from the CAD model that was unneeded in the FEA tool.

The integration of 3D CAD and FEA affected not only the technology in place at this SME, but also design and engineering processes. While there were increases in the amount of engineering effort, these increases were more than offset by reduced engineering rework and decreases in manufacturing effort achieved from improvements in the quality of the design. Additional benefits were also seen in the quality of sales proposals. 


\section{Abstract}

Small manufacturing enterprises face a number of challenges when integrating computeraided design (CAD) tools and computer-aided engineering (CAE) tools into their design processes. One of the most significant challenges is interoperability across the wide range of commercial CAD and CAE tools. Although many of these tools support industry data standards and claim to be interoperable, the connection between them is not seamless.

This report summarizes two case studies of tool integration activities at one small manufacturer. The first study examines the enhancement of the product development process resulting from replacement of a two-dimensional CAD system with a three-dimensional CAD system. The second examines the creation of an in-house capability to perform finite element analysis (FEA), replacing analysis that had previously been outsourced.

As a result of these experiences, the manufacturer learned that improved productivity and superior designs could be obtained by integrating analysis into the design process at the earlier stages of conceptual and preliminary design. The manufacturer also learned that the design process and some design techniques had to change for the company to use the CAD and FEA tools effectively. 


\section{Introduction}

\subsection{Small Manufacturing Enterprises and Technology Adoption}

Small manufacturing enterprises (SMEs) today are faced with many challenges, including global competition, volatile markets, and rapidly evolving technology. Meeting these challenges requires SMEs to raise their performance to a new level. They must operate with increased efficiency to meet the demands of global competition. They must re-engineer their development processes to reduce the time-to-market for new products. They must continually improve their products and services to meet ever increasing performance demands. To meet these challenges, many SMEs are turning to advanced information technology (IT) tools, including computer-aided design (CAD) and computer-aided engineering (CAE) tools.

At the same time, suppliers of CAD and CAE tools are offering simpler tools at a lower cost. Specifically, many CAE suppliers are producing "lite" versions of their most sophisticated tools for operation by casual users. These tools provide extensive features, intuitive user interfaces, enhanced tutorials and training, and expanded interoperability with other CAD and CAE tools.

Although this convergence between tool vendor capability and user need should drive a significant increase in the adoption of CAE tools by SMEs, there are constraints on the rate of engineering technology adoption. Resource constraints, as well as other barriers, affect SME identification and implementation of engineering tools [Robert 02]. When SMEs do invest in engineering tools, they often overlook the fact that success depends upon changing internal business processes to support the new tools.

\subsection{TIDE Program}

The United States Congress has long recognized the economic importance of SMEs. The U.S. Small Business Administration offers the following data [Crane 00]:

- $\quad 98 \%$ of all domestic manufacturing firms are SMEs.

- $39 \%$ of manufacturing employment is within SMEs.

- $25 \%$ of manufacturing output (in dollars) is from SMEs. 
- $65 \%$ of new jobs are created by SMEs [Garritson 98].

However, SMEs have typically been unwilling or unable to adopt advanced, commercial offthe-shelf (COTS) design tools. This reluctance may be attributed to various factors such as lack of awareness of tool availability and capability, lack of skills needed to use the tools, inadequate financial resources, inability to predict return on investment, etc. [TIDE 03]. To support this critical sector of the economy, in 1999 Congress established the Technology Insertion, Demonstration, and Evaluation (TIDE) program to “...demonstrate the cost savings and efficiency benefits of applying commercially available software and information technology to the manufacturing lines of small defense firms" [DoD 00].

\subsection{This Report}

One of the tasks of the TIDE program charter was to partner with several SMEs and demonstrate successful technology adoption efforts. The first of these partnerships involved an SME in the process of adopting three-dimensional (3D) CAD and finite element analysis (FEA) tools into his product development process.

This report discusses the processes and results of introducing these tools. Other reports provide detailed discussions of the tool selection process and the adoption evaluation process ${ }^{1}$.

Chapter 2 of this report describes both the technologies being adopted, and the state of the SME at the initiation of this program.

Chapter 3 presents the business goals of the SME and the strategies developed to pursue these goals. The two tools (CAD and FEA) were adopted on a series of projects; this chapter discusses the nature of these projects.

Chapter 4 presents an in-depth review of the adoption activities during the two selected projects.

Chapter 5 discusses the lessons learned by both the TIDE program and the SME as a result of the tool adoption processes.

Chapter 6 summarizes the results of the research, revealing that the new wave of engineering tools brings both risks and benefits to SMEs.

\footnotetext{
${ }^{1}$ Anderson, W. \& Estrin, L. A Case Study in Finite Element Analysis Tool Adoption for a Small Manufacturing Enterprise. Pittsburgh, PA: Software Engineering Institute, Carnegie Mellon University, 2003, and Robert, J.; Allinder, D.; \& Estrin, L. A Case Study in Finite Element Analysis Tool Adoption for a Small Manufacturing Enterprise. Pittsburgh, PA: Software Engineering Institute, Carnegie Mellon University, 2003. Both to be published.
} 


\section{Background}

\subsection{Engineering Tools and Technology}

\subsubsection{Computer-Aided Design (CAD) Functions}

CAD tools are the most common class of computerized tools used in the engineering and design process today. Introduced in the 1960s and much improved since then, these tools have replaced many of the drafting tables and machines used to generate engineering drawings. Early CAD tools were designed to produce a $2 \mathrm{D}$ representation of an item to be manufactured; many current $\mathrm{CAD}$ tools capture a $3 \mathrm{D}$ representation.

Most CAD tool suppliers target their products for use by designers and drafters, and feature intuitive, friendly, user interfaces. CAD tools capture a geometric model of the product to be built. The latest generation of 3D CAD tools is particularly well suited for the development of three-dimensional geometric models with all of the detail needed for manufacturing. From this model, the CAD packages can then produce the documentation needed for procurement and manufacturing. These CAD tools also include some capacity for the capture of material data, and the calculation of mass properties, although these capabilities may be limited. With these capabilities, CAD tools are typically the gateway to the CAE process ${ }^{2}$.

\subsubsection{Finite Element Analysis (FEA) Functions}

Although less widely used than $\mathrm{CAD}$, various CAE tools are also found throughout industry. Where CAD is used to define the form of the design item, CAE is used to define the function of the item. CAE tools provide the engineer with the ability to analyze, model, simulate, and optimize a design.

FEA tools are one common class of analytical CAE tools. FEA tools, when applied to a mechanical structure, offer the engineer insight into the stresses, deflections, modal frequencies, and mode shapes of the structure. In addition, FEA can be applied to other types of analysis, including heat transfer, electrostatic potential and fluid mechanics [Lee 99].

\footnotetext{
${ }^{2}$ Fenves, S.J.; Sriram, R. D.; Choi, Y.; Elm, J.; \& Robert, J. Advanced Engineering Environments for Small Manufacturing Enterprises, Volumes I and II. Pittsburgh, PA: Software Engineering Institute, Carnegie Mellon University, 2003. To be published.
} 
Like CAD tools, FEA tools also provide a means to capture a 3D representation of the item to be manufactured. The model generation facilities of FEA tools tend to be less user friendly than those of CAD systems, and are usually intended for use by a highly trained engineer or analyst. Furthermore, the model generation facilities generally offer only limited support for model details.

FEA tools also include facilities for the capture of material properties for the item. While these facilities are often less user friendly than those of CAD systems, they tend to be more comprehensive and more versatile. Once the geometry of an item is defined, the item is partitioned into a number of small elements by overlaying a three-dimensional mesh on the item (see Figure 1). A mathematical model based upon the element geometry and the defined material properties governs the response of each element to external stimulus (e.g., force or heat). The overall response of the item may be determined through the simultaneous solution of coupled element models. In this way, the static and dynamic response of the item is analyzed. Based upon this analysis, detailed reports showing stress, deflection, resonant mode shapes, and mode frequencies are generated.
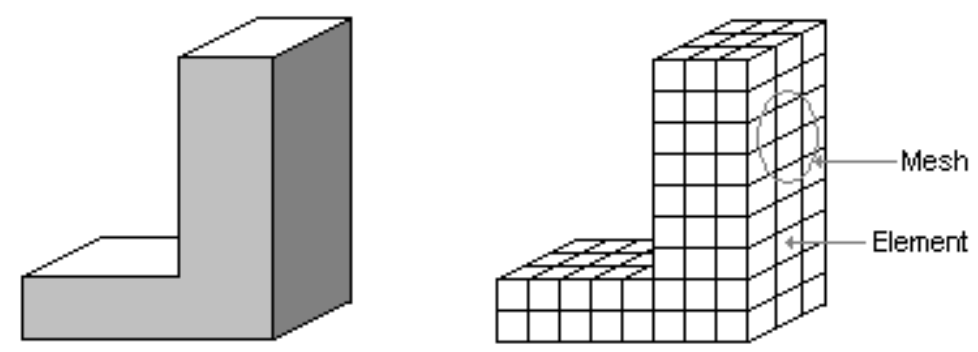

Figure 1: $\quad$ FEA Mesh Process

\subsection{SME Environment}

The business of the SME that is the subject of this paper is providing custom-designed, precision, electro-mechanical equipment to the aerospace industry. Each unit is built to meet specific, defined performance requirements from the customer. The units are typically constructed as assemblies of both custom-made and commercially available electrical and mechanical parts. In many cases, the mechanical production processes (e.g., machining or grinding) and mechanical assembly processes (e.g., alignment or measurement) used to manufacture this equipment are state of the art. 
To meet the performance requirements specified by the customer, the design must conform to certain critical performance factors (CPFs). The SME addresses these CPFs during the design process using various analytical tools. The design of the mechanical structure of the product is driven by the conflicting goals of

- optimizing structure size to meet payload requirements

- minimizing structure mass

- $\quad$ maximizing structure stiffness

- minimizing structural deflection under load

- maximizing structural mode frequencies

\subsubsection{SME Design Environment and Processes}

This section describes the design process in use at the SME prior to the involvement of the TIDE program. The design process is illustrated in Figure 2. 


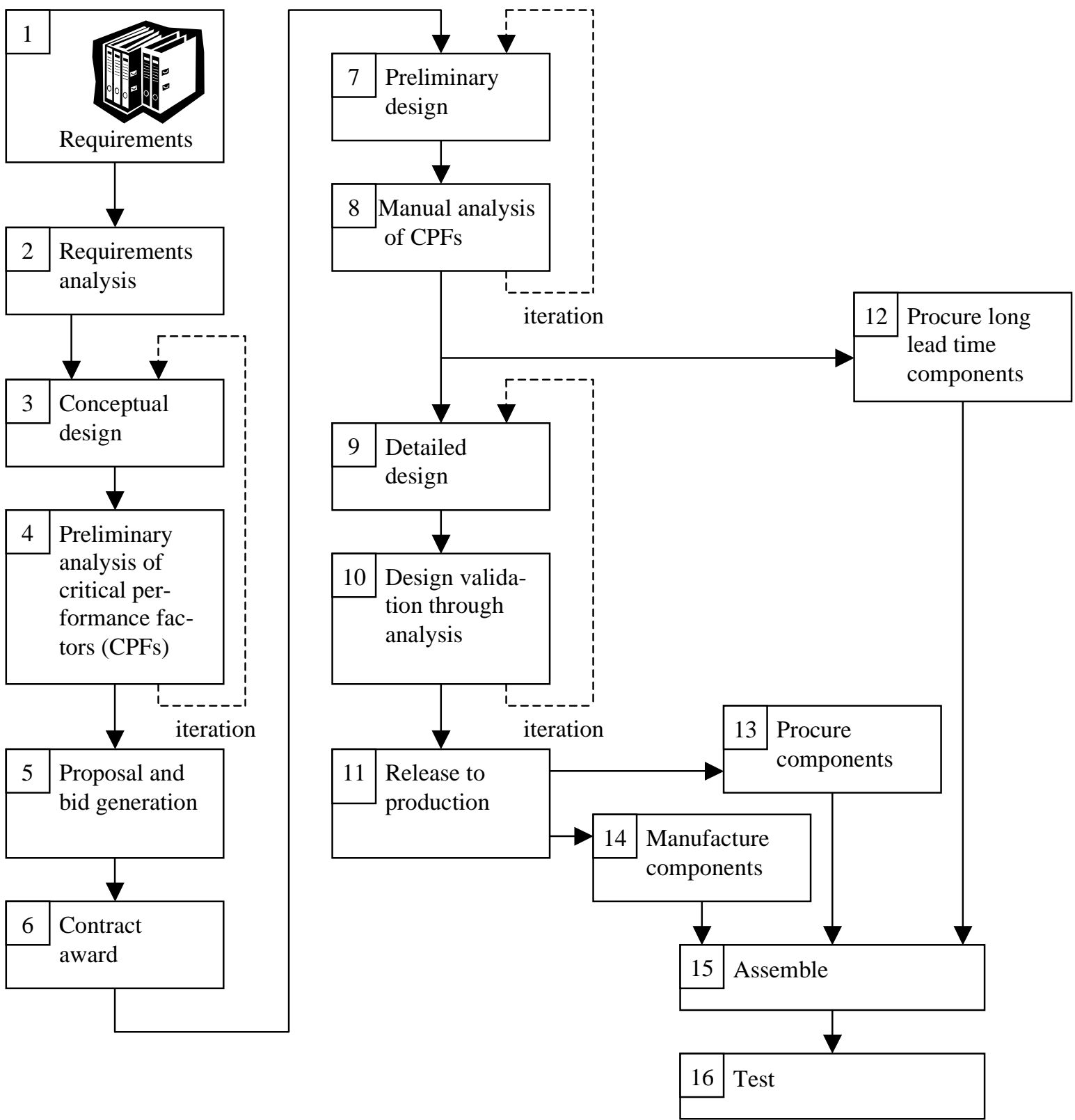

Figure 2: $\quad$ Design and Production Process

The design process begins with the initial inquiry from the customer. In response to a detailed set of customer requirements (Step 1 in Figure 2), the SME studies the requirements and develops a conceptual design (Step 3) using in-house CAD tools. This design is analyzed to assure conformance to CPFs (Step 4). Due to the need for rapid response and multiple iterations, the SME performs this initial analysis in-house to avoid delays typical in analytical subcontracting. Advanced analytical tools were not available within the SME; thus these ini- 
tial analyses are performed using manual calculation methods. The SME iterates the conceptual design/analysis process until the CPFs are met.

Based upon the conceptual design, the SME generates a detailed technical proposal and bid for submission to the customer (Step 5). Upon contract award (Step 6), the SME continues the design process with a preliminary design effort (Step 7) structured to initiate long-lead procurement activities (Step 12). During the final design effort (Step 9) the SME performs some design analysis using manual or computer-aided calculations. Due to the lack of detailed analysis, the designers attempt to assure conformance to the CPFs by making conservative (and often over-conservative) design decisions. After the design is completed, it is subjected to a design validation analysis (Step 10) to assure conformance to customer requirements. This final analysis is typically outsourced, and is performed using CAE tools such as FEA, kinematic modeling, dynamic modeling, or simulation. The validated design is then released for production (Step 11).

Prior to the TIDE program, all design efforts had been performed using 2D CAD tools. Because the CAD design consists only of a $2 \mathrm{D}$ representation of the product, the analyst must develop the 3D model required for FEA using the model generation capabilities of the FEA tool. This translation process is both time consuming and subject to the introduction of human error. In most cases, due to the conservative nature of the design decisions implemented throughout the design process, the results of the analysis meet or exceed the CPFs. However, if the analyst identifies a failure to achieve the CPFs, the analyst modifies the 3D model, and iterates the analysis. This continues until all CPFs are met. After completion of the analysis, the designers incorporate the design modifications generated by the analyst into the $2 \mathrm{D}$ manufacturing drawings. Once all requirements are satisfied, the SME releases the design for production. Figure 2 is a simplified diagram of this process.

\subsubsection{SME Engineering Tool History}

The SME had significant experience with CAD tools, initially adopting them in the 1970s. At that time, 2D CAD tools were used to produce 2D manufacturing drawings and the SME had become proficient with various $2 \mathrm{D}$ CAD tools. Prior to this project, the SME had no experience with 3D CAD tools, although several members of the design staff had previously used $3 \mathrm{D}$ CAD in their careers.

The SME had only limited direct experience with FEA tools. Ten years earlier, when the SME was a division of a much larger company, the SME had access to advanced FEA tools. These tools were operated by a group of highly trained analysts, whose sole responsibility was FEA. These experts were not employed by the SME when it was divested from the larger company. 
CMU/SEI-2003-TR-015 


\section{SME Goals and Strategies}

The SME established clear business goals to drive the engineering design process improvement. These business goals are summarized below:

- Reduce product performance risk. The equipment was custom-designed and manufactured to meet stringent performance specifications from the customer. Any error in engineering, design, or manufacturing could compromise performance. If not detected until final testing, correcting such an error could require disassembly, remanufacturing of mechanical components, reassembly, and retest, an expensive and time-consuming process.

- Achieve faster deliveries. Typical product delivery times could range from 3 to 24 months, depending upon the size and complexity of the product. Market pressures to reduce delivery times were apparent. Additionally, "opportunistic" sales could also be generated with shorter delivery times.

- Reduce costs. Increased competition was resulting in reduced prices for equipment. To maintain adequate market share and profit margins, cost reductions were needed.

- Enhance product performance. Markets were demanding continual increases in product performance. Superior performance was seen as a factor to distinguish the SME from the competition, as well as a route to commanding higher prices.

The SME devised three strategies to pursue these goals.

\section{Strategy \#1: Adopt 3D CAD and use an integrated model for product design.}

Replacement of existing 2D CAD tools with an advanced 3D CAD tool will allow the SME to create an integrated 3D model of the complete system. This model will include complete definitions of the interfaces between all components of the system. This strategy supported the goals of the SME as follows:

- Reduce product performance risk. This strategy was not targeted at reducing product performance risk.

- Achieve faster delivery. The 3D CAD system reduces the duration of the design cycle by replacing a time-consuming, error-prone, manual crosschecking process with an automated process that checks for interface mismatches between components. The 3D CAD model can also be used as the basis for FEA, eliminating the need to develop an additional model within the FEA tool. Finally, it reduces the duration of the manufactur- 
ing cycle through improvement in the accuracy of the design. The manual crosschecking process used previously to verify the interfaces of mating components was subject to human error and resulted in occasional failure. These errors were often not discovered until after the components had been manufactured. Correction of these errors required time-consuming design corrections, as well as rework or replacement of components. The automatic crosschecking capabilities of the 3D CAD tool could reduce the frequency of these errors, shortening the manufacturing cycle.

- Reduce costs. Reduction in the duration of the design cycle and manufacturing cycle (see above) will also result in a reduction of design effort and manufacturing effort, lowering costs.

- Enhance product performance. This strategy was not targeted at enhancing product performance.

\section{Strategy \#2: Use FEA to predict the performance of the product during the design cycle.}

Using FEA allows the SME to predict product performance and validate the design during the design cycle. FEA activities would be contracted to external experts. This strategy supports the goals of the SME as follows:

- Reduce product performance risk. The SME can identify and correct engineering and design deficiencies prior to manufacturing and assembly, significantly reducing the risk of performance failure.

- Achieve faster delivery. Identification of performance deficiencies during the design cycle enables the SME to correct them at that time. If these deficiencies were not discovered until testing, correction would require time-consuming design modification and rework or replacement of manufactured components.

- Reduce costs. Identification of design deficiencies during the design cycle enables the SME to correct them on paper, rather than revising metal after the components have been manufactured. This results in significant cost savings.

- Enhance product performance. This strategy was not targeted at enhancing product performance.

Strategy \#3: Use in-house FEA early in the design cycle to optimize the product design. 
Developing an in-house FEA capability allows the SME to use FEA as an integrated part of the design process, rather than as a post-design effort to validate the design. This strategy supports the goals of the SME as follows:

- Reduce product performance risk. The SME could use FEA to predict product performance during conceptual and preliminary design stages. This would enable the SME to optimize the design and ensure conformance to required performance.

- Achieve faster delivery. Prior to the availability of in-house FEA, analysis was done by an outside contractor after completion of the design process for the purpose of design validation. By this point, the 3D CAD model was nearly complete, and very rich in detail. Any changes indicated by the analysis resulted in considerable engineering effort to update the detailed 3D CAD model. In-house FEA capability enables the SME to perform analysis and performance prediction earlier in the design process, during the conceptual and preliminary design stages. At this point, the level of detail in the 3D CAD model is limited, making the incorporation of design changes mandated by the results of the FEA a relatively simple matter. Additionally, in-house FEA capabilities eliminate the need to wait for an external contractor to become available. Finally, maintaining in-house FEA expertise provides a means for the 3D CAD designers to better understand the interrelationships between the 3D CAD model and the FEA tool. This enables them to structure the 3D CAD model in ways that are compatible with the needs of the FEA tool. Reuse of the 3D CAD model by the FEA tool can be maximized, reducing the amount of time needed to construct a model for analysis.

- Reduce costs. The reduction in effort resulting from performing analysis on a less detailed model (see above) will produce cost savings. Additionally, the reduction in effort resulting from improved interoperability of the 3D CAD and FEA tools (see above) will also reduce costs.

- Enhance product performance. Because of an inability to predict final product performance during the design process, the designers have a tendency to "over-design," making conservative design decisions to ensure that performance criteria are met. Consequently, the resulting designs tend to be a little larger, a little heavier, a little costlier than needed. The ability to iteratively design and analyze during the conceptual and preliminary design efforts allows designers to optimize the design, eliminating over-design.

The SME devised a three-stage plan to implement these strategies.

1. Analyze and revise (if needed) the current design process to optimize it for the integration of 3D CAD and FEA.

2. Introduce $3 \mathrm{D}$ CAD into the design process.

a. Evaluate and acquire the appropriate 3D CAD tool. 
b. Acquire the appropriate resources (i.e., computer hardware) to support the 3D CAD tool.

c. Train the design staff on the use of the 3D CAD tool.

d. Establish monitoring processes to evaluate the effectiveness of the 3D CAD tool.

3. Introduce in-house FEA into the design process.

a. Modify the design process to use FEA during the early stages of design, rather than the current practice of using FEA for validation of a completed design.

b. Evaluate and acquire the appropriate FEA tool.

c. Acquire the appropriate resources (i.e., computer hardware) to support the FEA tool.

d. Train the design staff on the use of the FEA tool.

e. Establish monitoring processes to evaluate the effectiveness of the FEA tool.

\subsection{Project Selection}

This action plan was executed at the SME during the performance of two major contracts.

NOTE: The selection, use or presentation of a software product by the TIDE Program does not constitute an endorsement of that product by the TIDE Program, the SEI, Carnegie Mellon University or the Department of Defense.

For Project \#1, the SME received a contract to design, build, install, and test a precision electro-mechanical instrument for a major aerospace contractor. The complexity of the product, the stringent performance requirements, an aggressive schedule, and a lean budget presented significant challenges. To be successful, the SME needed to

- manage the complexity of the design

- ensure the accuracy of the design

- minimize the risk of performance deficiencies

- minimize the duration, effort, and cost of the engineering phase of the project

- minimize the duration, effort, and cost of the manufacturing phase of the project

The SME chose to use this project to introduce 3D CAD (SolidWorks ${ }^{\circledR} 2000$ ) into the operation. Steps 1, 2 and 3 of the action plan were implemented during this project.

() SolidWorks and SolidWorks 2000 are registered trademarks of SolidWorks Corporation in Concord, MA. 
For project \#2, the SME won a contract with a major government research laboratory to manufacture a precise electro-mechanical simulation instrument similar to systems previously supplied by the SME. While previous systems had more stringent performance characteristics, this project required significant cost control; the budgetary constraints of the customer demanded a product at a $20 \%$ lower cost. The customer and the SME entered into a study contract to define the characteristics of a system that could be offered within the budgetary constraints. Designing and producing the product at a cost consistent with this price demanded more efficient engineering and manufacturing practices. The adoption of a design paradigm featuring analysis and performance prediction early in the design stage supported this need. The SME decided to use this contract as a vehicle for the introduction of in-house FEA (ANSYS ${ }^{\circledR}$ version 5.7). Step 4 of the action plan was implemented during the performance of this contract.

The following chapters discuss these two projects.

( $\quad$ ANSYS is a registered trademark of ANSYS, Inc. in Canonsburg, PA. 


\section{Case Studies}

This section will present the chronology of each project. Analysis of these events and the findings of the researchers are found in Section 5.

\subsection{Case Study \#1 - Introduction of 3D CAD}

\subsubsection{The Project}

Case Study \#1 examines the first use of the 3D CAD tool at the SME. The project required the design of an electro-mechanical instrument consisting of approximately 800 customdesigned mechanical components, and 200 commercially procured mechanical components (motors, bearings, etc.). All of the CPFs described in Section 2.2 (optimal structure size, minimum structure mass, maximum structure stiffness, minimum structural deflection under load, and maximum structural mode frequencies) applied to this design. The SME applied the design process documented in Figure 2 to this project.

\subsubsection{Conceptual Design}

The statement of work accompanying the customer's request for proposal consisted of 49 pages detailing 187 individual requirements. The SME analyzed this document and formulated a conceptual design using 2D CAD tools. The SME then performed a preliminary analysis of the CPFs resulting from this design using internally developed computational tools. The predicted performance of the initial design with respect to the requirements was marginal. Additionally, it demanded the use of commercially procured motors that approached the state of the art in design and manufacturing. Furthermore, the cost of this design was estimated at $67 \%$ greater than the customer's budget. Due to the excessive cost, and the excessive performance risk, this proposed concept was judged to be unacceptable to both the customer and the SME.

Discussions were initiated with the customer, and a modification to the performance requirements was negotiated. Based upon this new set of requirements, a second conceptual design was developed. Preliminary analysis of this design revealed that performance margins of the CPFs were small, but acceptable. Furthermore, the estimated cost of this design met the customer's expectations. Based upon these factors, the SME was sufficiently confident to offer this design to the customer via a fixed-price contract. The proposed design is seen in Figure 3. 


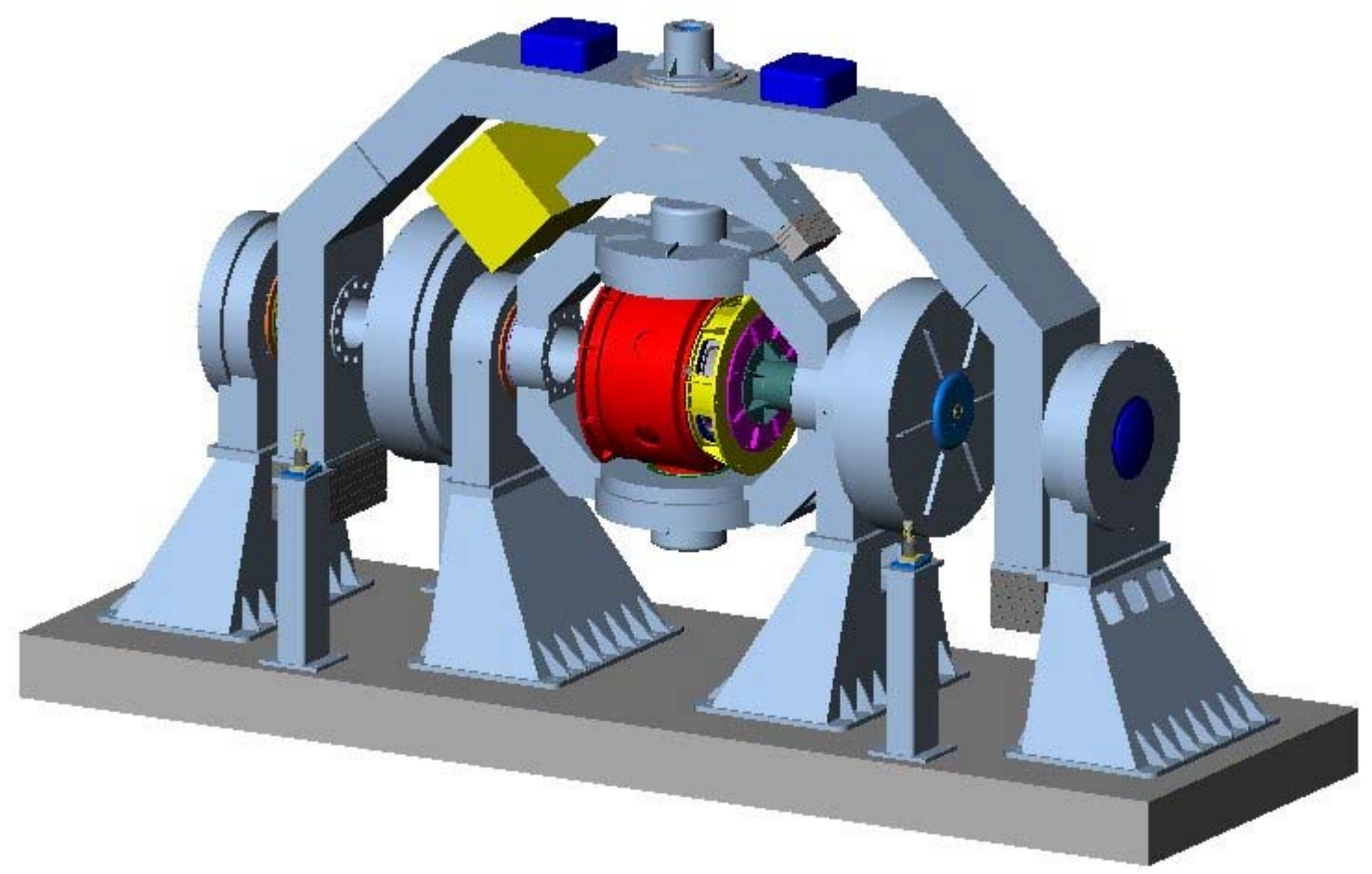

Figure 3: $\quad$ Proposed Design

\subsubsection{Introduction of 3D CAD}

As part of an on going program to improve design accuracy and efficiency, the SME had been evaluating the capabilities of several 3D CAD tools. Due to the size and complexity of this project, the SME management decided that the introduction of 3D CAD on this project would benefit both cost and schedule. The SME performed an informal comparison of several 3D CAD tools. Factors considered in the selection of the tool included

- $\quad$ product capabilities

- product usability

- $\operatorname{cost}$

- prior experience of design staff

- availability of local support 
Based upon these factors, the SME chose SolidWorks ${ }^{\circledR} 2000$ as the 3D CAD tool.

The 3D CAD tool was procured for the two designers assigned to the project. The existing computer hardware at the SME was insufficient to run this application. The SME acquired new computer systems for the two designers. The computers hosting the 3D CAD tool featured dual $866 \mathrm{MHz}$ CPUs, $512 \mathrm{MB}$ RAM, $32 \mathrm{MB}$ of video RAM, and $40 \mathrm{~GB}$ of disk storage. The computers ran the Microsoft ${ }^{\circledR}$ Windows 2000 Professional ${ }^{\circledR}$ Operating System with Service Pack \#1 installed. The computers were networked to a file server via a 100 baseT Ethernet link.

Both of the designers were proficient with similar 3D CAD products, and both were confident that their experience was applicable to this tool. Due to this confidence, and under pressure to minimize the cost impact of adopting this new technology, the SME management elected to attempt adoption of the 3D CAD tool without the benefit of formal training. During the initial phases of the adoption, this approach seemed justified. After just a few days of study and experimentation, both designers were able to begin the creation of 3D designs with acceptable proficiency. With this newly acquired capability, the design team embarked upon the design of the new product.

\subsubsection{Product Design with an Integrated Product Model}

The product design phase begins with a preliminary design. Previously, when utilizing 2D CAD tools, the designer would develop a system layout. This document would include orthogonal planar views of the equipment, as well as planar cross-sections. The individual components to be designed would be shown in these views. This layout would serve as the basis for the design of these individual components. Each component would then be "extracted" from the layout for design completion. New drawings showing orthogonal views of each component with all necessary manufacturing details would be generated. After all of the individual components were designed, a manual checking process was performed to ensure that all components were consistent with the layout, and that all inter-component interfaces correlated (e.g., dimensions and tolerances were consistent, bolt hole patterns were consistent).

The use of a 3D CAD tool during the preliminary design effort enabled the SME to produce an integrated 3D model of the entire product. This integrated model served the same purpose as the layout drawings developed on 2D CAD; however, the 3D model contained the complete set of component designs embedded within it. During the preliminary design stage, individual components were represented by "placeholders," simplified models estimating the fundamental shape and size of the component, but lacking significant detail. Later in the design phase, the designer could develop each component individually, with the resulting de-

(B) Microsoft and Windows 2000 Professional are registered trademarks of Microsoft Corp. in Redmond, WA. 
tailed design being automatically incorporated into the complete system 3D model. In this manner, correlation of the components with the system design was assured, and the correlation of component interfaces was simplified. Interface discrepancies became readily apparent, and many were automatically identified by the 3D CAD tool. This greatly simplified the checking process, and reduced the occurrence of design errors that remained undetected until they reached the production floor.

Based upon the preliminary design and analysis, procurement efforts for components with long lead times were initiated. This process was essential in order to maintain the project schedule; however it added an element of risk to the program because design errors involving these items could be costly to fix later in the project. For example, if the continuing design effort or the design validation process (Step 10 in Figure 2) identifies a performance deficiency, a modification of the design will be needed. Two scenarios may arise, either of which can compromise the success of the project.

1. The design modifications must be constrained to avoid impact upon the components already on order. This may lead to a non-optimal design.

2. The design modifications may demand modifications to the components already on order, resulting in increased costs and schedule delays.

During the final design the configurations of the individual components were defined, captured, and incorporated into the integrated 3D model. As this effort proceeded, the designers encountered some difficulties. The mechanical system consisted of both custom-designed and standard purchased components and both classes of components were included in the integrated model. As the design process progressed, the "placeholders" from the preliminary design were expanded to a complete and detailed representation. Hundreds of these components were assembled to form the integrated model. As a result, the integrated model contained all of the information embodied within these individual component models, as well as the information needed to define their interrelationships. The file size of the integrated 3D CAD model exceeded $37 \mathrm{MB}$, with purchased components as high as $1 \mathrm{MB}$ each and custom components as high as $0.5 \mathrm{MB}$ each. This excessive model size led to a number of problems during the design process.

The model data was stored on a central server, enabling access from any of the design stations linked to it by a 100 baseT Ethernet network. Nevertheless, loading the model from a remote drive over a LAN connection often required up to eight minutes. Even loading the model from the local PC hard disk drive required approximately three minutes. Additionally, as changes were made to the model, the designer periodically performed a rebuild operation. With large models, this could take up to 16 minutes to rebuild both the model sheet and the detail sheet. 
The SME made contact with the local value-added reseller (VAR) for the 3D CAD tool to discuss these issues. To control model size, the VAR referred the SME to strategies developed by 3D CAD user groups [WMUG 01], and also added specific recommendations based upon the needs of this SME [Vasalani 01]. The VAR provided these strategies to the SME as summarized below.

Load assembly components as lightweight. Use "lightweight components" within the 3D $\mathrm{CAD}$ tool to allow for the loading of the solid geometry while leaving out the parametric information or "instructions" of the part model. Components being edited and used for relationships are resolved as needed.

Suppress non-essential components. Suppress components that are not being edited and are not being used for relationships to reduce the file size and the amount of information to rebuild. Specifically, hardware components (e.g., nuts, bolts), while integral to the design, are typically not design critical. Whenever possible, hardware components are suppressed in all configurations where they are not actually needed for the design process. Meanwhile, a "complete" design configuration is maintained with complete hardware for use on drawings or bill of material (BOM) purposes.

Use assembly configurations. The 3D CAD tool offers the ability to create configurations that define which features are active and which are suppressed. Use these configurations to enable the user to create model subsets that manipulate parts faster, while still having the ability to view the entire model. Keep a configuration of the entire model, and create simplified representations (managed by configurations) with all non-essential components suppressed.

Use subassemblies. Working in subassemblies reduces rebuild time. Open subassemblies in a separate file to avoid having to open the entire model. The changes to the subassembly will automatically update the top-level assembly when it is opened. As at the top level, configurations are used at the subassembly level to create simplified representations with all nonessential components suppressed.

Use advanced show/hide. The advanced show/hide tool allows groups of parts to be easily selected and turned on or off, and it works very fast. Populate all parts in a large assembly with custom properties such as "material," "revision," "built by," "part number," "purchased part," or "hardware." The user can use both advanced show/hide selection and advanced component selection to quickly sort through an entire assembly and turn specific components on or off.

Use envelope zones. Envelopes allow a user to select and turn off parts within a specific geometric volume. Use envelopes in conjunction with part properties to perform sophisticated part queries. 
Load components from the local drive. Working from the computer's local drive is much faster than working from the network. Download all necessary files from the network to the local hard drive, and perform all design modifications from the local hard drive. After the changes are complete, upload the files to the network location. When multiple designers are working on a file, take care to ensure that changes from one do not overwrite the changes from the other. A product data management (PDM) system could be helpful in this endeavor.

Lock references. Use the "lock reference" command to lock an individual part's external references. In an assembly with many part-to-part relationships, regeneration of one part can automatically trigger the regeneration of many other parts in the assembly. By locking the external references of the part, the assembly will skip rebuilding that part's external references. The designer must use this feature cautiously, since the lock function will also prevent the 3D CAD tool from temporarily updating the assembly with the full parametric design intent.

Develop a company standard for component design. Robust component, or part, design for performance is an entire topic by itself because part design is very application specific, and therefore company specific. What works well for one company will not always work well for other companies, which is why every company should develop its own in-house standards for design. However, there are several important general guidelines, fundamental to the development of any company standard, worth mentioning here.

a. Minimize use of lofts and sweeps. Both lofts and sweeps are computationally and graphically intensive features. They should be used sparingly and only when called for by the design at hand.

b. Eliminate detail for industry standard or off-the-shelf parts. Avoid the creation of models for off-the-shelf or industry-standard components in full detail for use in an assembly. Only show enough detail to ensure form, fit and function of the design. If purchasing drawings or marketing materials require full detail, create a detailed configuration and a simplified configuration. The simplified configuration should only show only design-critical features.

c. Simplify models of industry-standard components. CAD files of industrystandard components are often downloadable from manufacturers' Web sites. These component models tend to be fully featured, containing much more detail than is required for incorporation into an integrated assembly model. This 3D CAD tool provides an easy way to create a simplified model. Export the part from the 3D CAD tool (typically in Parasolid ${ }^{\circledR}$ format) and then re-import the part. This produces a "dumb" solid, with all features of the model shown, but as a simple imported body rather than as individual features.

d. Avoid patterns. While the use of patterns is an effective method to leverage the full power of the 3D CAD tool's parametric modeling ability, it is also computationally intensive. Patterns should be used only when necessary.

\footnotetext{
${ }^{\circledR}$ Parasolid is a registered trademark of EDS.
} 
e. Create fillets and chamfers last. Fillets and chamfers require significant computational resources. In parts that must have many chamfers and fillets, create a simplified configuration that suppresses all fillets and chamfers not critical to the design. This simplified configuration should always be used in the simplified configuration of any assemblies containing these parts. When creating fillets and chamfers, create all fillets and chamfers of the same size in one operation. Create the fillets and chamfers as the very last features in the part to make them easy to find for suppression, and to avoid the creation of unnecessary relationships between the fillets, chamfers and subsequent features.

f. Leverage part symmetry. To avoid creating more individual features than necessary, use the mirror commands at the sketch and feature levels to quickly duplicate symmetrical features.

In addition to resolving the immediate problems, this interaction with the VAR made apparent the value of training for the 3D CAD tool. While the SME's design staff leveraged their knowledge of other 3D CAD tools to achieve rapid productivity on this new tool, their lack of training made it difficult to use all the features of the new tool effectively. This deficiency was easily, although belatedly, overcome by the SME with the purchase of training for all designers and engineers.

In addition to minimizing model size, the SME also enhanced the communication network within the facility. With these changes, delays associated with model loading and model rebuilding were reduced to an acceptable level.

\subsubsection{Initial FEA}

FEA was outsourced to an engineering service firm experienced in engineering analysis using the ANSYS FEA tool (version 5.5.3). The services of this firm had often been used on previous projects using 2D CAD for the design efforts. The original intent was for this firm to generate a 3D model based upon the final design, using the model generation capabilities of the FEA tool. With the availability of the 3D model from the 3D CAD tool, the firm chose to import this model rather than construct a new model within the FEA tool. The 3D CAD tool supports the export of data in several formats, including Initial Graphics Exchange Standard (IGES), Standard for the Exchange of Product Model Data (STEP), and Parasolid. With the software available at the engineering service firm, IGES was the only compatible file format for communication between the 3D CAD and FEA tools.

Problems arose with attempting FEA on this imported model. The 3D CAD model had been developed solely with the goal of producing manufacturing drawings. As a result, it contained a great deal of detailed design information (e.g., edge fillets, threaded bolt holes). When transferred to the FEA tool, the result was an unacceptably large model. 
IGES is not ideally suited for the transfer of data between 3D CAD and FEA. IGES was originally designed to transmit surface data, rather than solid models. As a result, when the 3D CAD model was converted for transmission via IGES, it was reduced to a "shell" representation of the model, and data defining each surface was transmitted (i.e., a solid cube of material would be sent as six individual surfaces: front, back, top, bottom, left, and right). Features in the model such as fillets and chamfers were not transmitted, and resulted in gaps between these surfaces. The resulting FEA model consisted of thousands of independent surfaces, some connected, and some unconnected. The resulting data in the FEA model was too massive and confusing for the analyst to comprehend and simplify. Working this way, the analyst and the FEA tool could not build an integrated model.

To circumvent these problems, the analyst individually imported each component of the 3D CAD model. Each of these components also suffered from the same problems of IGES mistranslation and excessive detail. However, the resulting FEA model of each individual component was sufficiently simple that the analyst could identify and manually correct the deficiencies. From each component, the analyst removed the unneeded detail (e.g., bolt holes, fillets) and reconnected all discontinuous surfaces using a "stitch" function within the FEA tool. After all of the model components were imported and corrected in the FEA tool, the analyst then reconstituted the complete model by reassembling all of the components.

The imported and reconstructed FEA model still lacked some information needed by the FEA tool. The 3D CAD model was in the form of an assembly of fully defined mechanical components. All geometrical relationships between components were defined (e.g., surfaces concentric, surfaces parallel). The FEA tool was successful at importing the geometry; however, additional information was needed to properly define the relationships of the parts. Surfaces identified as "welded" on the 3D CAD model needed to be locked together in the FEA model using a "glue" function. Many components in the 3D CAD model were bolted together; within the FEA model, either the relationship between the mating surfaces could be represented as glued or the bolts themselves could be modeled. In most cases, the glue relationship was used.

When meshing was applied using the automatic meshing functions of the FEA tool, the residual detail contained in the 3D CAD model forced the generation of a much finer mesh than was needed for the FEA. The resulting meshed model exceeded the processing requirements of the analyst's computer resources, a PC with $512 \mathrm{MB}$ of RAM and a CPU operating at a clock rate of $500 \mathrm{MHz}$. When analysis of the large model was attempted, the FEA tool ran for a period of 72 hours without reaching a solution.

Clearly, another method of generating a FEA model was necessary. 


\subsubsection{Adapting to CAD and FEA}

Both the SME and the analyst realized the advantages of maintaining a single 3D model used in both the 3D CAD tool and the FEA tool. Because the FEA model would be electronically derived from the CAD model, the opportunity for the introduction of human error during the generation of the FEA model would be eliminated, thereby ensuring close conformance between the CAD and FEA models. Additionally, it is often necessary to iterate the design and analysis effort several times to find a design to meet the CPFs of the project. Using the CAD model as a basis for the FEA model would allow the designer to make changes with the more user-friendly CAD tool, and then export the updated model to the FEA tool.

The root problem with the model transfer was the amount of detail included in the CAD model. The CAD and FEA tools have contradictory requirements. The CAD tool demands a detailed geometric description for the generation of comprehensive manufacturing documentation, while the FEA tool is compromised by excessive detail. Instead, it requires a geometric model consisting of fundamental shapes and sizes. The SME decided to reorganize the CAD model in a manner that satisfied both the CAD and the FEA requirements.

The 3D CAD tool includes tools that assist in this reconfiguration. In the 3D CAD model, geometry is defined on two levels:

- Sketched features. Sketched features are solid models establishing the fundamental geometry of the object. Designers generate a planar representation of the shape, and extrude it in a third dimension. Multi-stage extrusions enable the production of complex threedimensional shapes.

- Applied features. Applied features are characteristics that directly modify the solid model, without changing its basic shape. Applied features include edge chamfers, edge fillets, and bolt holes.

In creating a complete 3D model, typically the designer begins with the elemental shape, using sketched features, and then adds the required details via applied features. The 3D CAD tool has the ability to layer the design. Thus, the elemental shape may be contained on one set of layers, while the details may be distributed over a different set of layers. The 3D CAD tool can also enable or disable selected layers. Careful use of these capabilities provides a solution to the conflicting requirements of CAD and FEA models. All of the fundamental geometry needed by both the CAD and the FEA tools may be segregated onto one set of layers in the 3D CAD model. All of the additional detail, needed by the CAD tool but superfluous to the FEA tool, is placed onto a different set of layers. With this drawing organization, the second layer set may be enabled to permit the CAD tool to produce the detailed drawings needed for manufacturing. To perform FEA analysis, the second layer set is disabled. This defeatured model represents only the fundamental geometry, and will produce a more manageable FEA model. 


\subsubsection{Back to FEA}

The defeatured 3D CAD model was once again transferred to the FEA tool using the IGES format. Due to the limitation of the IGES format (see Section 4.1.5), the model was transferred one component at a time. The component models were corrected in the FEA tool, and reassembled into a complete model. With the importation of the defeatured 3D CAD model, the resulting FEA model remained large, but was now manageable. As before, the additional component relationship information (such as gluing, etc.) was added using the model generation capabilities of the FEA tool. Meshing was applied using the manual mesh generation capabilities of the FEA tool to produce a mesh resolution consistent with the needs of the FEA. The resulting model consisted of 117,000 elements and 143,000 nodes. Execution time of the analysis was reduced to approximately eight hours, and was completed successfully.

Not unexpectedly, the results of the FEA predicted some deficiencies in the design's conformance to the CPFs. Armed with the analytic results, the engineers and designers returned to the 3D CAD model and began making design modifications. The presence of extensive design details in the 3D CAD model complicated the incorporation of these design modifications. Even though the design fundamentals were segregated from the design details, changes in the elemental shapes had some impact upon the design details (i.e., holes required relocation, fillets were added when new gussets were added). Upon completion of the design modifications, the SME repeated the process of defeaturing, transfer to the FEA tool, model augmentation in the FEA tool, meshing, and analysis. The SME performed six design iterations to achieve full compliance with the CPFs.

\subsubsection{Manufacturing}

After appropriate reviews, the final design was released for production. Detailed manufacturing drawings were extracted from the 3D CAD model for each individual component. Components available from commercial suppliers (e.g., motors, bearings, bolts) were procured. Custom-made parts (e.g., castings, weldments, forgings) were fabricated in accordance with the drawings. Each component was subject to an inspection upon receipt to ensure compliance with critical aspects of the production documentation (e.g., dimensional accuracy, material properties). Noncompliant components were returned for correction or replacement. The SME initiated the assembly process once the components had been inspected and accepted.

On previous projects, prior to the introduction of 3D CAD, the personnel assembling the product would sometimes encounter interface discrepancies between the components (e.g., a bore in one piece would be too small to accept the boss of a mating piece; a bolt circle in one flange would not mate with the bolt circle of a mating flange). These discrepancies rarely could be traced to manufacturing errors not discovered during the inspection process. More commonly, they could be traced to errors in the design process. The components were manufactured according to specifications; however, the specifications were incorrect. These design errors were primarily the result of human error in the design process which had remained un- 
detected by the manual process of checking component drawings against the system layout and other component drawings (see Section 4.1.4).

Interviews of production personnel confirmed that the introduction of 3D CAD made a significant difference in this area. They stated that they had encountered fewer difficulties during the mechanical assembly of the system than they had for systems designed prior to the incorporation of the 3D CAD system. The production documentation for the project also bears witness to this fact. When design errors are encountered during the assembly process, the designers and engineers must generate an engineering change notice $(\mathrm{ECN})$ to document the correction. On this project, only one ECN was generated during the mechanical assembly process. This was a significant decrease from the average of 12 to 15 ECNs for similar projects. In addition, this single ECN resulted from a design error incorporated into the manufacturing drawings without updating the 3D model.

\subsubsection{Test and Delivery}

After assembly, the final unit was tested and found to be in compliance with all specifications. The finished product was shipped and installed successfully at the customer's facility. The finished product is shown in Figure 4. 


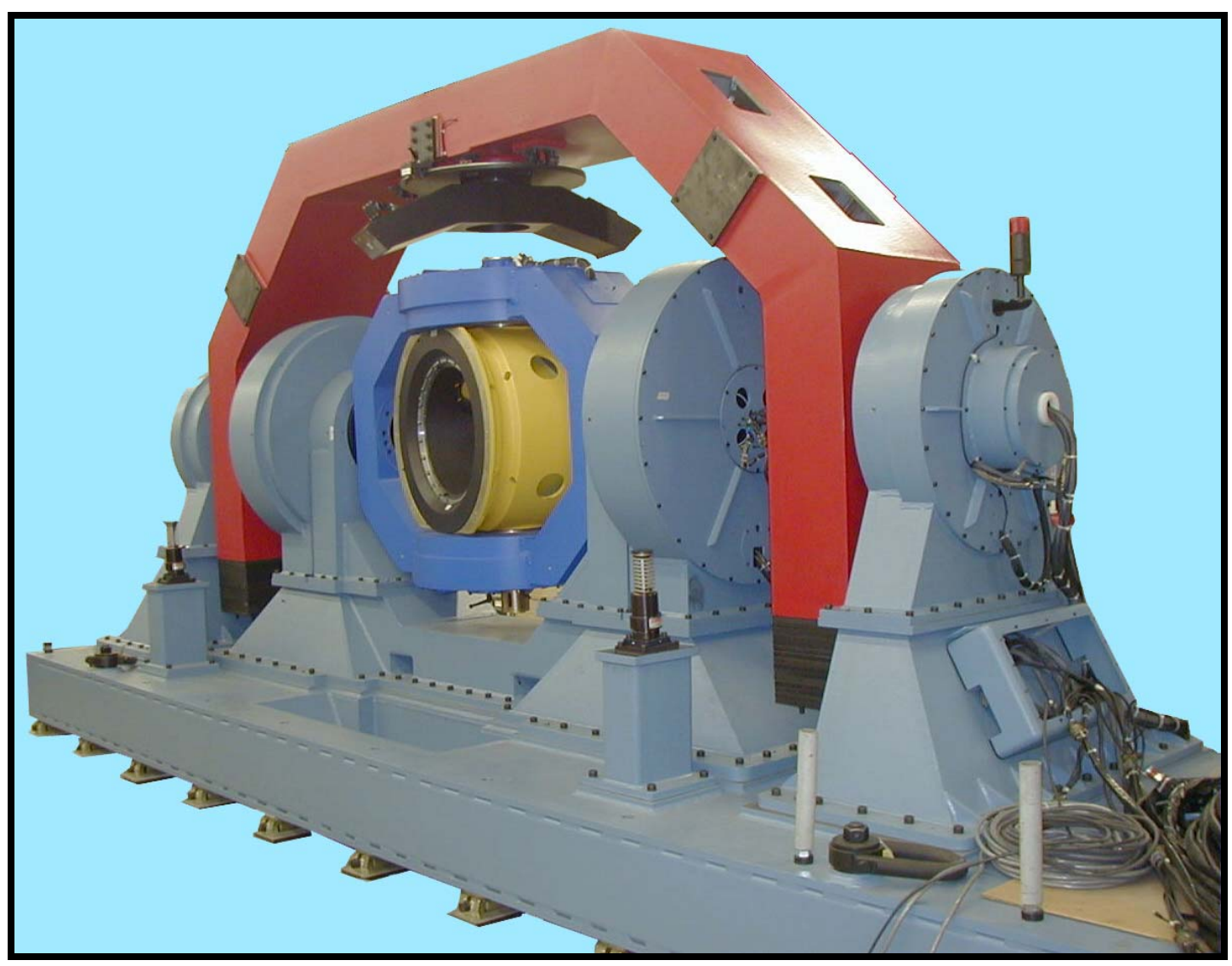

Figure 4: $\quad$ Finished Product for Case Study \#1

\subsection{Case Study \#2 - In-House FEA}

\subsubsection{The Project}

Case Study \#2 examined the first internal use of the finite element analysis tool at the SME. The project required the design of a mechanical system consisting of 85 custom-designed mechanical components, and 75 commercially available mechanical components. The SME had previously produced similar products, but this system required customization to meet the unique requirements of the application and achieve the cost target. All of the CPFs previously described (optimal structure size, minimum structure mass, maximum structure stiffness, minimum structural deflection under load, and maximum structural mode frequencies) applied to this instrument design.

This project was unusual in that the SME did not create a proposal in response to a specification developed by the customer. Instead, the SME was contracted to analyze the customer's needs and develop a performance specification. This unique project also offered an opportunity to analyze the design using the new FEA capability. 
Additionally, the SME modified the design process, with the intent of using the in-house availability of FEA to reduce program risk. As discussed in Section 4.1.4, procurement of purchased components with long lead times was done after the preliminary design in order to support the required schedule. This introduced risks that subsequent design changes resulting from analysis would either be constrained by the desire to avoid affecting the components on order, or would introduce cost and schedule problems if they did affect these components. To reduce this risk, the SME used the FEA tool earlier in the design process, during the preliminary design activity (Step 7 in Figure 2) In this manner, the SME achieved a higher level of confidence that the preliminary design was correct and that design revisions were not likely to occur later. The revised design and production process is shown in Figure 5. 


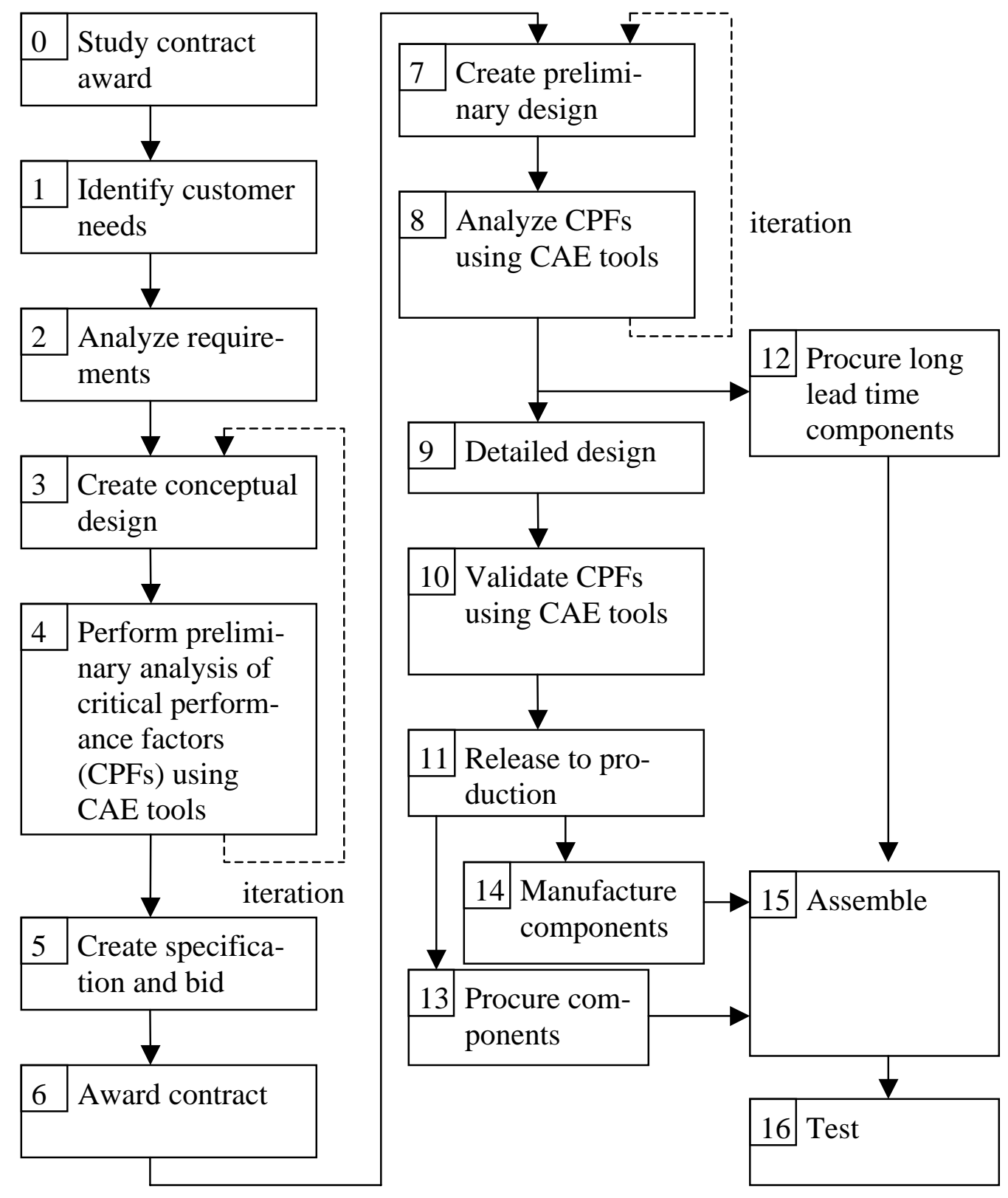

Figure 5: $\quad$ Modified Design and Production Process

\subsubsection{Introduction of In-House FEA}

As discussed in Section 2.2.1, historically the SME had outsourced the FEA effort with the primary purpose of mitigating the risk of performance failure by validating the performance projections of a completed design. With in-house availability of FEA, the SME could control and minimize the time required to perform an analysis. Instead of using FEA for design validation at the end of the design process, the SME could use it for design optimization throughout the process. FEA could replace the manual analysis operations of Step 4 in Figure 
2, as well as the analysis occurring in Steps 7 and 8. With comprehensive and timely analysis, the designers could optimize the design for the specified functionality, and eliminate the conservative design practices that result in over-designed products.

The SME considered several commercially available FEA tools and chose the ANSYS FEA tool (Version 5.7) based upon specific evaluation criteria. The evaluation criteria were created and prioritized by a team of stakeholders including management, engineers and designers. The evaluation was facilitated by TIDE personnel using COTS evaluation techniques [Wallnau 98]. The evaluation criteria included factors such as local support, analysis capabilities, interoperability with the existing 3D CAD tool, usability, cost, and prior experience. For the SME, the biggest factor that drove the FEA tool selection was the local availability of vendor support, including training and consulting.

After identifying an FEA tool, the SME and the TIDE team developed a technology adoption plan that included the following procurements:

- FEA tool: The FEA tool was purchased with a node locked license so that one workstation would be the primary station for performing analysis, but a designer or engineer could review the results from any workstation.

- Computer workstation: The existing computer hardware at the SME was insufficient to efficiently run this application. The SME acquired a new computer system featuring a 1 GHz CPU, 512 MB of RAM, 64 MB of video RAM, and 40 GB of disk storage. The computer ran the Microsoft Windows 2000 Professional Operating System with Service Pack \#1 installed, and was networked to a file server via a 100 baseT Ethernet link.

- FEA tool training: The SME engineers and designers assigned to the project went through the basic FEA training course which covered the use of the FEA tool.

- FEA tool consulting: The SME acquired flexible consulting support to provide on-site consulting as needed. An hourly rate and budget limit were set and only support above the normal tool support was charged. This was important because some support was provided as part of the purchase of the FEA tool.

\subsubsection{Conceptual Design and Analysis}

Since this project was not defined by a comprehensive performance specification, the first step in project execution was the identification of the customer needs. This was based upon a review of the current and projected tasks to be performed by the customer with the mechanical system. The SME then defined the critical performance factors of the system, and formulated a conceptual design using the 3D CAD tool. Users of similar equipment delivered previously had experienced several mechanical failures. The SME studied these failures and determined that these previous systems contained a design deficiency. In the new design, the SME corrected this deficiency. 
Using the already complete 3D CAD model, and the ready availability of the FEA tool, the SME performed a preliminary analysis of the design to evaluate the CPFs. Unlike the earlier case study, this later version of the FEA tool offered improved interoperability with the 3D CAD tool. Model data could be exchanged between the tools using IGES, STEP. or Parasolid formats. Furthermore, the CAD model being analyzed was only an early-stage conceptual model. It included the major structural elements but, unlike the previous case study, it did not include the extensive amount of detailed information that created a challenge for the FEA tool. As such, the 3D CAD model was easily transferred to the FEA tool. Transfer of the 3D CAD model to the FEA tool was accomplished via the following process.

1. The model was exported from the $3 \mathrm{D}$ CAD tool in a Parasolid format, and then imported into the FEA tool.

2. Additional component relationship information (e.g., gluing) was added using the model generation capabilities of the FEA tool.

3. Meshing was applied using the manual mesh generation capabilities of the FEA tool.

To achieve the defined CPFs, multiple preliminary design iterations were required. Changes to the physical model were made in the 3D CAD tool and transferred to the FEA tool. Due to the absence of large amounts of design detail, the design iterations could be accomplished quickly. For each iteration, 3D CAD modifications were typically made in less than one hour. The transfer to and model augmentation in the FEA tool took a few hours for the initial iteration, but required less than one hour for the final iteration. After six preliminary design iterations, the SME achieved sufficient confidence in the conceptual design to offer it to the customer via a fixed-price contract. This design is seen in Figure 6. 


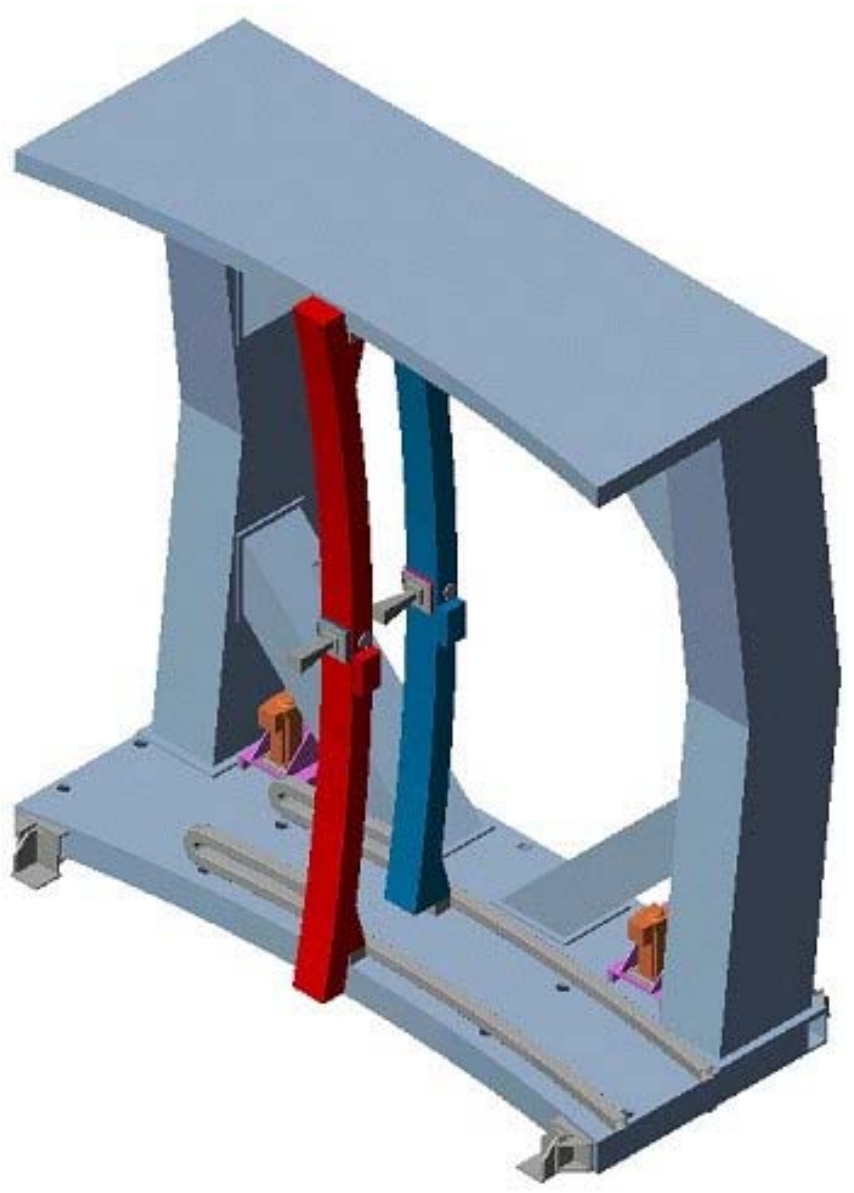

Figure 6: $\quad$ Conceptual Design from Study Contract

\subsubsection{Preliminary Design}

Based upon the conceptual design and analysis, the SME was awarded the contract for the design and production of the equipment. The SME commenced a preliminary design process, focused upon defining and initiating procurement of those components with extended lead times. This design was based upon the conceptual design previously generated, and added the detailed information necessary to fully define the components to be purchased or fabricated. At the completion of the preliminary design process, the manufacturing drawings for all longlead components were complete.

The conceptual design had already defined the fundamental geometry of the primary components using the 3D CAD tool. During the preliminary design process, additional detail was added to new layers of this model. In a few cases, the incorporation of details and definition of component interfaces forced minor modifications in the fundamental geometry of the components. In these cases, the modifications were incorporated onto the base layers of the model. 
At the completion of the preliminary design process, the SME performed a FEA to ensure that none of the incorporated modifications had compromised the CPFs. To perform this analysis, the detail layers of the 3D CAD model were suppressed, leaving only the fundamental geometry, including the design modifications. This model was then transferred to the FEA tool. The resulting FEA model consisted of 61,619 elements and 144,820 nodes and was 515 $\mathrm{KB}$ in size. The model was analyzed, and showed no compromise of the CPFs.

The SME continued through the final design phase. This design phase added detail information for the remaining system components, and produced the manufacturing and procurement documentation. This detail was again segregated on separate layers of the 3D CAD model. The incorporation of details and definition of component interfaces forced several minor modifications in the fundamental geometry of the components. In these cases, these modifications were incorporated onto the base layers of the model.

At the completion of the final design process, the SME performed a final FEA to ensure that none of the incorporated modifications had compromised the CPFs. Again, the detail layers of the 3D CAD model were suppressed, leaving only the fundamental geometry, including the design modifications. This model was transferred to the FEA tool; the resulting FEA model consisted of 86,108 elements and 161,208 nodes and was $664 \mathrm{~K}$ in size. The model was analyzed, and showed no compromise of the CPFs, as analyzed previously during the conceptual design phase.

\subsubsection{Final Design}

The SME observed that the in-house FEA capability was important for quantifying the performance impact of design decisions. For example, the SME used the FEA tool to perform six iterations of the preliminary design; when the FEA analysis was outsourced, just one FEA iteration of the final design was typically conducted. As a result, the SME was able to optimize the design to balance the performance requirements of the customer with the design tradeoffs that drive cost. Using the FEA tool, the SME could analyze the model to see whether or not a stiffening beam or component was really needed to support the performance requirement. In some cases the component was removed or reduced in size, resulting in reduced costs. Two iterations in the final design phase further optimized cost and performance.

In addition, the SME found that in-house FEA capability enabled them to offer additional services to their customer. Specifically, the customer was very concerned with preparation of the installation site. The customer knew the installation site should provide proper support and stability for the instrument, but was unsure if the current installation site would be appropriate. The SME saw this as an opportunity and generated a model of the installation site, integrated it with the instrument model, and performed an analysis of this integrated system. This analysis revealed that the customer needed to modify the design of the site to provide adequate support for the instrument. When the SME shared an early version of this analysis 
with the customer, the customer increased the contract funding to pay for an additional, detailed analysis, as well as future refinements of the analysis. This is a clear example of how the in-house FEA provided financial benefits, risk mitigation benefits and customer satisfaction benefits for the SME.

\subsubsection{Manufacturing, Test and Delivery}

The SME realized several benefits during the manufacturing of the system for Project \#2.

First, the SME encountered only two design errors, significantly below the average for similar projects. This was also observed in Project \#1 and was likely due to the use of the interference checking features of the 3D CAD tool.

A final design was developed with some further optimization of the cost and performance requirements. At the time of this report, the final assembly is in progress and testing will begin shortly after the assembly is completed. Although testing has not been performed to validate the performance requirements, the FEA analysis has been validated based upon the SME's experience with previous versions of this same system. The final design is shown in Figure 7. 


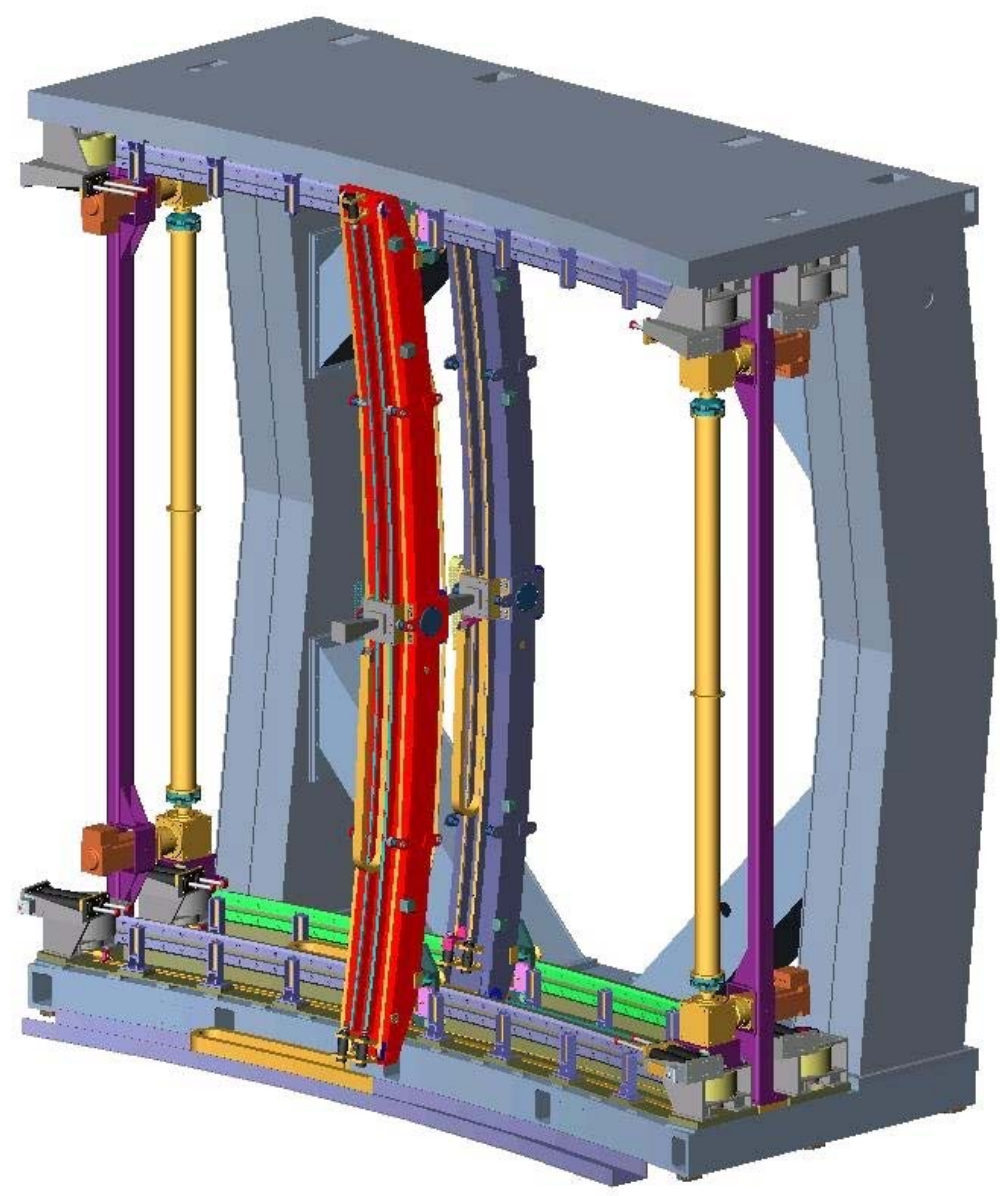

Figure 7: $\quad$ Final Design for Project \#2 


\section{Lessons Learned}

The lessons learned by the SME from the integration of the 3D CAD tool and the FEA tool may be divided into three categories:

- design process lessons

- 3D CAD lessons

- FEA lessons

\subsection{Design Process Lessons}

The most significant impact of the 3D CAD and FEA integration arose from changes in the design process.

\subsubsection{FEA for Design Optimization}

As described in Section 2.2.2, the SME had previously used FEA for design validation purposes after completion of the design. Due to the conservative design choices made during the design process, the FEA usually confirmed that the equipment would conform to the required $\mathrm{CPF}$; however, the equipment was usually over-designed, resulting in excessive manufacturing cost and time.

The incorporation of FEA into the early phases of the design process expands the analysis effort from a validation process to an optimization process. Now, after a relatively small design effort to produce a design concept (i.e., a design containing the fundamental information needed to define the equipment, but lacking the details needed for equipment manufacturing), the FEA tool can be used to predict conformance to the CPFs. Instead of ensuring conformance to the CPFs by employing conservative design decisions, the design and analysis process can be iterated to produce a result that meets the CPFs without being over-designed. The avoidance of over-design has several beneficial impacts.

- It reduces product cost.

- It enables the SME to offer higher performance systems to customers. 


\subsubsection{Model Generation Using CAD}

As discussed in Section 2.1.1, the SME may derive benefits from the use of a single 3D model to support both CAD and FEA activities. As discussed in Sections 2.1.1 and 2.1.2, both the 3D CAD tool and the FEA tool provide capabilities for 3D model generation. This offers the SME the opportunity to use either or both tools for model generation.

Using the CAD tool for the creation and maintenance of 3D models proved to be the most efficient method. While the FEA tool could be used to generate such a model, neither the FEA tool nor the 3D CAD tool support the ability to transfer that model from FEA to CAD. Furthermore, while the model generated by the FEA tool is suitable for FEA, it cannot be expanded to produce the documentation needed for manufacturing. This would necessitate the generation of a second 3D model using the 3D CAD system, causing duplication of effort, potential introduction of human error, and maintenance of model correlation.

The 3D CAD tool can also produce a 3D model of the equipment. Furthermore, it can interpret this model to produce the drawings required for manufacturing. Finally, using layering techniques to segregate the fundamental structure from the manufacturing detail, it is possible to produce a 3D model suitable for FEA. Using the 3D CAD tool to produce and maintain the 3D model offers a number of advantages.

- It ensures that all models, even those not subjected to FEA, are built with a common tool.

- It generates a 3D model that is suitable for both the development of manufacturing documentation and the performance of FEA.

- It generates a 3D model that may be exported to the FEA tool.

- It eliminates the need for the designers to learn to use the model definition interface of the FEA tool.

For these reasons, all model development, revision, and maintenance activities should be done using the 3D CAD tool.

\subsection{D CAD Lessons}

\subsubsection{Integrated Model}

The 3D CAD enabled the SME to create an integrated 3D model of the entire product, as opposed to individual designs of each component. With the integrated model the SME can correlate each of the components and their interfaces with the product design. In fact, the 3D $\mathrm{CAD}$ tool automates many of these correlations. This computer-aided process replaces the manual process of checking individual component designs to ensure correct interfaces, and 
can greatly reduce the number of design errors that remain undetected until the product reaches the production floor.

\subsubsection{Large Assembly Management}

One of the challenges of creating an integrated model is to manage the overall model size. If a model is too big, the result is a long wait while loading the model from storage, or while the 3D CAD tool rebuilds the model during editing, as discussed in Section 4.1.4.

There are a number of methods to manage model size.

- Load assembly components as lightweight.

- Suppress non-essential components.

- Use assembly configurations to define active and suppressed features.

- Work within subassemblies whenever possible.

- Use advanced selection criteria (e.g., advanced show/hide) to select groups of parts for suppression.

- Use envelope zones to select groups of parts for suppression.

- Load components from the local drive rather than from network drives.

- Lock references of components to avoid inadvertent regeneration when working on other components.

- Design components to avoid computationally intensive operations (e.g., loft and sweep, patterns) and to segregate computationally intensive features (e.g., fillets, chamfers)

- Use simplified models of industry standard or off-the-shelf parts.

- Leverage part symmetry whenever possible.

\subsubsection{Structure Model to Suit FEA Needs}

To maximize the efficiency of transferring the 3D CAD model to the FEA tool, the needs of the FEA tool must be considered during the development of the 3D CAD model.

As discussed in Section 4.1.6, it is essential that the designer control the level of detail provided to the FEA tool. This is readily accomplished through the segregation of basic geometry and manufacturing detail within the 3D CAD model. Work processes must be established, and designers must be trained to ensure that segregation is handled consistently. 


\subsubsection{Training}

The intuitive nature of the user interface of many of the 3D CAD tools is at once helpful and deceptive. It is helpful in the sense that it makes using the tool easy. It is deceptive in the sense that it may lure the SME into the trap of adopting the tool without the benefit of enough formal training. This SME began using the 3D CAD tool without training because several of the designers had training on other 3D CAD tools. The designers quickly grasped the 3D CAD tool interface, and became productive in a matter of just one week. However, later, when trying to integrate FEA into the design process, the SME discovered that the 3D model lacked several key attributes.

- The model lacked the appropriate hierarchical structure to facilitate FEA.

- The model lacked the appropriate segregation between fundamental geometry and manufacturing detail to facilitate defeaturing for FEA.

- The model included custom-designed components, where simpler library components could have been used.

- Design techniques used in the generation of the model created an unnecessarily large number of features to be managed.

Some of these deficiencies affected the performance of the 3D CAD efforts and others were not exposed until the CAD model was used with FEA. These deficiencies contributed to CAD and FEA interoperability issues and delays in the first case study.

Had the SME procured the appropriate training prior to the development of this first model, many of these pitfalls could have been avoided. As part of this TIDE study, the SME designers received professional training on the use of the 3D CAD tool during the final design of the first case study. The training addressed the issues mentioned above and presented techniques to correct the deficiencies. The trainer's knowledge of both the CAD and the FEA tools enabled her to address both the issues affecting CAD and those involving interoperability with FEA. As a result of the 3D CAD training, the SME designers were able to improve the use of the 3D CAD tool and minimize integration time between the 3D CAD tool and the FEA tool.

\subsection{FEA Lessons}

\subsubsection{Interoperability with 3D CAD}

The most successful design process consisted of generating the models for use in the FEA tool using the 3D CAD tool. Once the 3D CAD model was created, it was exported to the FEA tool for analysis. As the need for design modifications was revealed by the analysis, the 
model updates were performed in the 3D CAD tool and the model was re-exported to the FEA tool for further analysis. Several benefits accrued from this process.

- The design staff did not have to develop proficiency in using the model generation capabilities of the FEA tool.

- The design staff updated the models more efficiently with the more user-friendly 3D CAD tool user interface.

- Complete correlation between the design used for manufacturing and the design used for analysis eliminated errors introduced during creation of an independent FEA model.

Success is predicated upon achieving rapid and reliable transfer of 3D CAD models to the FEA tool. Two factors were found to have a significant impact upon model transferability.

- Model complexity: As discussed in Section 5.2.3, the designer is required to pay attention to the model configuration needed by the FEA tool while creating the design in the 3D CAD tool. Within the 3D CAD model, the designer must segregate cosmetic features (i.e., features not essential to equipment performance, such as fillets and chamfers) from structural features (i.e., features that do impact equipment performance). With appropriate segregation, the designer could exercise the feature suppression capabilities of the 3D CAD tool to simplify the model for analysis, a process known as "idealization." Without idealization, the model presented to the FEA tool could be too complex for timely analysis. This requirement points to a need to develop guidelines for the design staff to ensure a model configuration amenable to defeaturing.

- CAD - FEA Model Sharing: The 3D CAD tool and the FEA tool support multiple data protocols for exportation and importation of data. Both support IGES, STEP, and Parasolid transfer protocols. As detailed in Section 4.1.5, model transfers using IGES were not successful. Model transfers using STEP were much better, but still not completely predictable and consistent. Model transfer using the native Parasolid format provided the most accurate and consistent results. The Parasolid format does introduce one complication: it converts all aspects of the design into metric units. When starting with a design based upon English units, the analyst must use caution in interpreting the analytical results, which will be presented in a metric format.

\subsubsection{Meshing}

FEA requires dividing the structure to be analyzed into small "elements," each considered to be physically homogeneous. This process is called "meshing" because it resembles overlaying a 3D mesh on the structure. In these studies, this step proved to be more time consuming and complex than anticipated. Choosing a mesh that is too coarse (using big elements) reduces accuracy of the FEA analysis. Choosing a mesh that is too small can dramatically increase the computation time required for the analysis. Another contributing factor is that meshing should be as automated as possible to minimize labor time to prepare a 3D model for FEA analysis. However, automatic meshing algorithms tend to create a large number of 
small elements, increasing computation time. Therefore, the best meshing provides a good balance between accuracy, automation, and computation time.

Prior to analysis, it is difficult to predict the relationship of accuracy and computational time to element size. One method of assessing these tradeoffs involves iterative analyses using decreasing element sizes. The initial iteration is done using large elements and analysis results and computation times are recorded. For subsequent iterations, a smaller element size is used. As the elements get smaller, the analysis results converge asymptotically to the "correct" values, while the computation times increase geometrically. For each iteration, the incremental change in the analysis results will become smaller, while the incremental change in the computation time will become larger. The analyst continues the iterative process until the small changes in results no longer justify the large increases in computation time.

\section{Table 1: $\quad$ Mesh tradeoff example}

\begin{tabular}{|l|l|l|l|}
\hline \multicolumn{1}{|c|}{ Mode Frequency } & \multicolumn{1}{|c|}{$\begin{array}{c}\text { Element size of } \\
\mathbf{1 5}\end{array}$} & \multicolumn{1}{|c|}{$\begin{array}{c}\text { Element size of } \\
\mathbf{1 0}\end{array}$} & $\begin{array}{c}\text { Difference between } \\
\text { analysis results }\end{array}$ \\
\hline \hline Mode 1 & 14.201 & 13.935 & $1.87 \%$ \\
\hline Mode 2 & 21.688 & 21.049 & $2.95 \%$ \\
\hline Mode 3 & 28.156 & 27.131 & $3.64 \%$ \\
\hline Number of Elements & 22657 & 33327 & 10670 \\
\hline Computation Time & $<1$ hour & $\sim 2$ hours & 1 hour \\
\hline
\end{tabular}

Table 1 provides an example of how element size impacts analysis accuracy and computation time. The data in the second column shows the results of the analysis based upon larger (size 15) elements, while the data in the third column show the results of the analysis using smaller (size 10) elements. This data shows that using smaller elements increased the analysis time by more than an hour; however, analysis results changed by less than $4 \%$. The task of the analyst is to decide when the point of diminishing returns has been reached. In this example, if a variation of mode frequencies on the order of $4 \%$ is not significant to the performance of the product, there is no need to proceed with analysis iterations using smaller elements.

At first, meshing was performed using the automated meshing function within the FEA tool. With this method, the computation time became unacceptably long (around eight hours for some of the analysis). After some discussion with the vendor, manual meshing was performed on key sections of the model to simplify the mesh and therefore reduce the analysis time. Specifically, models with large variations in volume size would not mesh using the available automated meshing functions. One solution to this problem was to mesh the small 
volumes first with a small mesh size and then to mesh the larger mating volumes with a larger mesh size. With this method, it was possible to keep the model element count within the solvable range. While this technique worked, it did require some manual intervention, and took some practice on the part of the analyst to find a balance between the amount of time spent manually meshing the model versus the amount of computation time needed for model solution.

Training the SME employees to perform manual meshing also took some time, but was accelerated by on-site consulting support from the vendor, who demonstrated manual meshing on a real product model. Initially, only one employee was trained to perform the meshing and preparation of models for analysis. Eventually, other employees developed these skills, but the complexity of meshing and gluing (see below) continued to limit the use of the FEA tool to only a few employees.

\subsubsection{Gluing}

The limited interoperability between CAD and FEA systems becomes very evident during the idealization process that converts the CAD model to one suitable for FEA. After importing a 3D model from the CAD tool into the FEA tool, many parts must be "glued" together to provide constraints for the FEA tool when performing various types of analysis. For example, structural steel shapes that are welded together must be glued in the FEA model, as shown in Figure 8 .

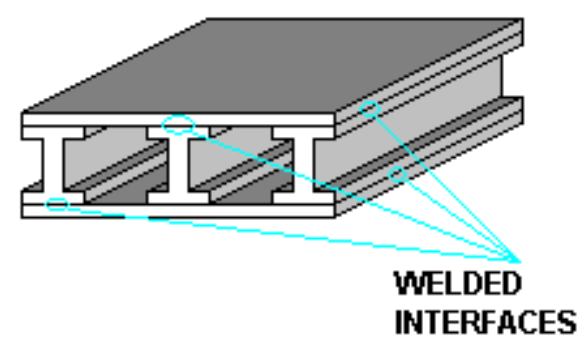

3D CAD MODEL

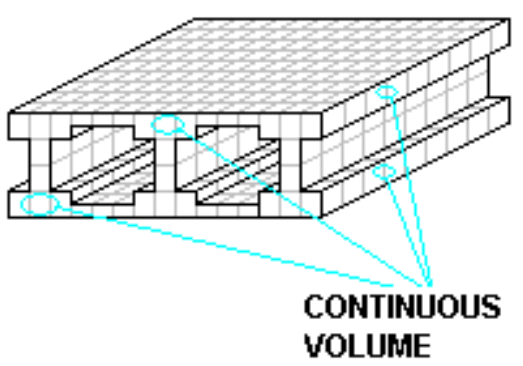

GLUED FEA MODEL

Figure 8: $\quad$ Glue Function

However, the data interoperability standards between the 3D CAD tool and the FEA tool do not include exchange of the glue information largely because these model constraints are not needed for CAD operations but are required for analysis. The glue function step proved to be problematic because 
- The "pick all" function did not work consistently. Sometimes individual parts had to be glued together manually, which added considerable labor time between analysis iterations because this manual glue function had to be repeated every time the 3D model was revised and imported back into the FEA tool.

- Additional training was required for the user to support the glue function. Specifically, the user was most concerned with

- What characteristics limited the "pick all" function?

- How were glued parts tracked?

- How was the final model checked for unglued parts?

When the glue function didn't work, the vendor suggested using the overlap function or the merge function. The merge function didn't seem to work well in this application, but the overlap function worked well enough to support the user's needs.

\subsubsection{Ease of Use}

Usability was a concern during the selection of a FEA tool, but proved to be an even greater issue during the remainder of the project. At the time that the FEA tool was adopted by the SME, the FEA tool market was changing from a market of a few high-end tools to a split market that included high-end and low-end FEA tools. FEA tools were following the pattern of 3D CAD tools; tools that were once expensive and targeted at specialists (high end) were spawning a wave of simpler to use and less expensive FEA tools (low end). The low-end tools also have limited functionality, including less control over meshing and no ability to perform non-linear analysis.

This SME chose a high-end FEA tool, but gaining added functionality also meant that the tool was harder to use. For example, the FEA tool enabled the SME to support detailed analysis of systems, but the tool's complexity also limited its use to a couple of engineers. A lowend FEA tool would have limited the types of analysis, but would have enabled the SME to have designers perform preliminary FEA analysis earlier in the design process. This discovery led the SME to eventually pursue a hybrid FEA tool approach with both high-end and low-end tools to support basic analysis by designers early in the process and more detailed analysis as needed throughout the design process.

\subsubsection{Training and Consulting Support}

Training and consulting was a focus area from the beginning of the project and proved to be very valuable. Training and flexible consulting support were needed for both the 3D CAD tool and for the FEA tool.

For training, the design and engineering team members first participated in a basic two-day 3D CAD course because few of the people had been formally trained in 3D CAD tools. This 
training resulted in several improvements in using the CAD tool, including different modeling approaches when exporting the model into the FEA tool and better use of assembly features.

After the CAD tool training, the engineers and designers attended a basic four-day FEA tool course. This course included an introduction to FEA concepts and training on the FEA tool. This training also proved useful and resulted in

- the introduction of FEA concepts to the entire design and engineering team

- a common understanding of the FEA tool capabilities and terminology

- examples of using the FEA tool to solve real problems

Despite the success of the training, consulting support also had a critical role in two key areas. First, the consulting filled the gap between the training provided by the vendor and the knowledge required to apply the tool to real SME design issues. The vendor training was general tool training and proved to be insufficient for engineers to walk into their office and begin using the FEA tool. The consulting support enabled the SME to ask the FEA tool consultant to work on site with engineers to address real SME design issues. The SME engineers worked on the design and called the consultant when they had a question. This approach enabled the SME engineers to become productive with the FEA tool more quickly without having to work though problems by themselves.

A second area where consulting support proved very important was risk management. Using a FEA tool, or any CAE tool, can be risky because the tool uses a model to predict system response and the model can be incorrect. The model can be wrong for any number of reasons, including poor modeling assumptions or incorrect application of a stimulus to the model. Risk identification is particularly difficult because the answer from an FEA analysis can appear to be correct, but may in fact be wrong. To assist in FEA risk management, the flexible consulting support was used to monitor the proper use of the FEA tool and review initial analysis reports. Specifically, the consultant reviewed FEA analysis results on-site with the SME and identified any tool or modeling issues. Eventually, this consulting review activity was performed by SME engineers in a peer review process, but the early use of consulting support proved critical to success. On one occasion, the review identified an improper analysis constraint, but this was corrected before it could have any adverse impact on the design. 


\section{Summary}

Integration of 3D CAD and FEA into a design engineering environment can have a wideranging effect upon an SME. The SME must approach the integration activity as a technology adoption process rather than a singular event, recognizing that changes in technology, process, staff skills and staff responsibilities will be required. This report demonstrates that SMEs can successfully adopt 3D CAD and FEA technology by managing key issues within the adoption process.

- Tool adoption drives process changes. Incorporation of tools into the product development process may necessitate changes in that process. At a minimum, procedures will be needed to ensure the appropriate and effective use of the tool (e.g., model size management procedures, CAD-FEA compatibility procedures). In many cases, changes will be needed in the design process itself (e.g., design optimization versus design validation).

- Interoperability is critical. Identifying and understanding different levels of tool interoperability is critical for the selection of tools and the identification of process changes that may be required to work around limitations. Previous efforts in engineering tool integration indicate that tool interoperability will evolve as the market and tools mature, but acceptance of engineering tools requires users to understand the interoperability both across tools and with the engineering process [Wallnau 91].

- Tool adoption may demand changes in staff skill sets. Incorporation of new technology may necessitate changes in human resources. Changes in skill levels, work assignment, and staffing may be needed. At a minimum, personnel skill levels will need to be augmented through training addressing the use of the tool, as well as new design processes driven by the tool. The SME must plan (and budget for) this training. Due to the intuitive nature of a tool's user interface, it may be possible to utilize the tool without training. However, subtle, non-intuitive issues arise when trying to use the tools together. Appropriate training can address these issues. In more severe cases, changes in the distribution of work assignments among personnel may be needed to place the tools in the most effective hands. In the worst cases, personnel changes could be required.

- IT infrastructure changes may be needed. Incorporation of new tools can affect the IT infrastructure of the SME. More powerful computer stations or faster networks may be required.

The adoption of 3D CAD and FEA tools described in this report is an example of how software tools can have an important effect on SMEs in today's manufacturing market. Success- 
ful adoption of these tools brings SMEs one step closer to the engineering environments that are today emerging in larger manufacturers. 


\section{Acronyms}

2D

3D

BOM

CAD

CAE

COTS

CMU

CPF

ECN

FEA

GB

IGES

IT

MB

NIST

RAM

SEI

SME

STEP

TIDE two dimensional

three dimensional

bill of material

computer-aided design

computer-aided engineering

commercial off-the-shelf

Carnegie Mellon University

critical performance factor

engineering change notice

finite element analysis

gigabyte $\left(10^{9}\right.$ bytes)

Initial Graphics Exchange Standard

information technology

megabyte $\left(10^{6}\right.$ bytes)

National Institute of Standards and Technology

random access memory

Software Engineering Institute

small manufacturing enterprise

Standard for the Exchange of Product Model Data

Technology Insertion, Demonstration, and Evaluation 
CMU/SEI-2003-TR-015 


\section{References/Bibliography}

All URLs are valid as of the publication date of this report.

[Crane 00]

[DoD 00]

[Garritson 98]

[Lee 99]

[Robert 02]

[TIDE 03]

[Vasalani 01]
Crane, W. M. \& Hopkins, T. D. The Impact of Regulatory Costs on Small Firms. Washington, DC: The Office of Advocacy, U.S. Small Business Administration, 2000.

Department of Defense Appropriations Act, 2000.

<http://thomas.loc.gov/cgi-bin/query/z?c106:h.r.2561.enr:>

Garritson, D. \& Schwarzwalder, R. Small and Medium Manufacturers: The Heart of Our Economy. Washington, DC: National Association of Manufacturers, 1998.

Lee, K. Principles of CAD/CAM/CAE Systems, 1st ed. Boston, MA: Addison-Wesley, 1999.

Robert, J.; Buhman, C.; Garcia, S.; \& Allinder, D. "Bringing COTS Information Technology into Small Manufacturing Enterprises," Proceedings of the 2nd International Conference on COTS-Based Software Systems, Ottawa, Canada, Feb. 10-12, 2003. Ottawa, Canada: National Research Council Canada, 2003.

<http://www.iccbss.org/2003/abstracts.html\#robert>

TIDE Program Overview.

<http://www.sei.cmu.edu/tide/overview/overview.html>

Vasalani, D. Large Assembly Best Practices. Pittsburgh, PA: Mallett Technology, 2001. 
Wallnau, K.; Carney, D.; Morris, E.; Oberndorf, T.; \& Buhman, C. "Tutorial on the Theory and Practice of COTS Software Evaluation," Proceedings of the 1998 Software Engineering Symposium. Pittsburgh, PA, Sept. 14-17, 1998. Pittsburgh, PA: Software Engineering Institute, Carnegie Mellon University, 1998.

<http://www.sei.cmu.edu/cbs/cbs_slides/98symposium/eval_tut /index.htm>

[Wallnau 91] Wallnau, K. \& Feiler, P. Tool Integration and Environment Architectures (CMU/SEI-91-TR-011, ADA237810). Pittsburgh, PA: Software Engineering Institute, Carnegie Mellon University, 1991. $<$ http://www.sei.cmu.edu/publications/documents/91.reports /91.tr.011.html>

[WMUG 01] Solidworks Western Michigan Users Group, Assembly Best Practices. 2001.

<http://westmug.org/download/assembly_best_practices.doc> 


\begin{tabular}{|c|c|c|c|c|}
\hline \multicolumn{3}{|c|}{ REPORT DOCUMENTATION PAGE } & \multicolumn{2}{|c|}{$\begin{array}{l}\text { Form Approved } \\
\text { OMB No. 0704-0188 }\end{array}$} \\
\hline \multicolumn{5}{|c|}{ 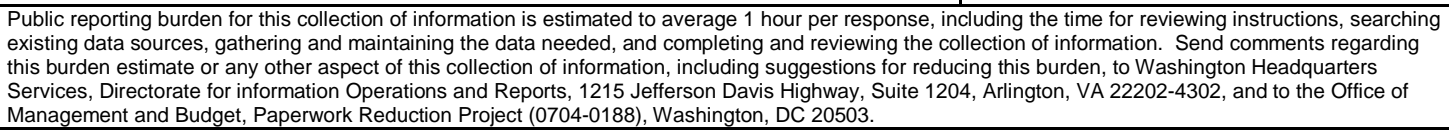 } \\
\hline $\begin{array}{ll}\text { 1. } & \text { AGENCY USE ONLY } \\
\text { (Leave Blank) }\end{array}$ & \multicolumn{2}{|l|}{$\begin{array}{l}\text { 2. } \\
\text { JEPORT DATE } \\
\text { June } 2003\end{array}$} & \multicolumn{2}{|c|}{$\begin{array}{ll}\text { 3. } & \text { REPORT TYPE AND DATES COVERED } \\
& \text { Final }\end{array}$} \\
\hline \multicolumn{3}{|c|}{$\begin{array}{l}\text { TILEAND SUBTTLE } \\
\text { Integration of Computer-Aided Design and Finite Element } \\
\text { Analysis Tools in a Small Manufacturing Enterprise }\end{array}$} & \multicolumn{2}{|c|}{$\begin{array}{ll}\text { 5. } & \text { FUNDING NUMBERS } \\
& \text { F19628-00-C-0003 }\end{array}$} \\
\hline \multicolumn{5}{|c|}{$\begin{array}{ll}\text { 6. AUTHOR(S) } \\
\text { Joseph P. Elm, John E. Robert }\end{array}$} \\
\hline \multicolumn{3}{|c|}{$\begin{array}{l}\text { 7. PERFORMNG ORGANZATONNAME(S) AND ADDRESS(ES) } \\
\text { Software Engineering Institute } \\
\text { Carnegie Mellon University } \\
\text { Pittsburgh, PA } 15213\end{array}$} & \multicolumn{2}{|c|}{$\begin{array}{ll}8 . & \text { PERFORMNG ORGANZATION } \\
\text { REPORT NUMBER } \\
\text { CMU/SEI-2003-TR-015 }\end{array}$} \\
\hline \multicolumn{3}{|c|}{$\begin{array}{l}\text { 9. SPONSORING/MONTORING AGENCY NAME(S) AND ADDRESS(ES) } \\
\text { HQ ESC/XPK } \\
5 \text { Eglin Street } \\
\text { Hanscom AFB, MA 01731-2116 } \\
\end{array}$} & \multicolumn{2}{|c|}{$\begin{array}{l}\text { 10. SPONSORING/MONTORING AGENCY } \\
\text { REPORT NUMBER } \\
\text { ESC-TR-2003-015 }\end{array}$} \\
\hline \multicolumn{5}{|l|}{ 11. SUPPLEMENTARY NOTES } \\
\hline \multicolumn{3}{|c|}{$\begin{array}{l}\text { 12A DISTRIBUTIONAVAILABIUTY STATEMENT } \\
\text { Unclassified/Unlimited, DTIC, NTIS }\end{array}$} & \multicolumn{2}{|c|}{ 12B DISTRIBUTIONCODE } \\
\hline \multicolumn{5}{|c|}{$\begin{array}{l}\text { Small manufacturing enterprises face a number of challenges when integrating computer-aided design (CAD) } \\
\text { tools and computer-aided engineering (CAE) tools into their design processes. One of the most significant } \\
\text { challenges is interoperability across the wide range of commercial CAD and CAE tools. Although many of } \\
\text { these tools support industry data standards and claim to be interoperable, the connection between them is not } \\
\text { seamless. }\end{array}$} \\
\hline \multicolumn{5}{|c|}{$\begin{array}{l}\text { This report summarizes two case studies of tool integration activities at one small manufacturer. The first } \\
\text { study examines the enhancement of the product development process resulting from replacement of a two- } \\
\text { dimensional CAD system with a three-dimensional CAD system. The second examines the creation of an in- } \\
\text { house capability to perform finite element analysis (FEA), replacing analysis that had previously been out- } \\
\text { sourced. }\end{array}$} \\
\hline $\begin{array}{l}\text { 14. SUBJECT TERMS } \\
\text { CAD, FEA, manufactl } \\
\text { tools }\end{array}$ & g, SME, technology adopti & gineering & \multicolumn{2}{|c|}{$\begin{array}{l}\text { 15. NUMBER OF PAGES } \\
67\end{array}$} \\
\hline \multicolumn{5}{|l|}{ 16. PRICECODE } \\
\hline $\begin{array}{l}\text { 17. SECURTY CLASSIFCATION } \\
\text { OF REPORT } \\
\text { Unclassified }\end{array}$ & $\begin{array}{l}\text { 18. SECURTYCLASSIFCATONOF } \\
\text { THSPAGE } \\
\text { Unclassified }\end{array}$ & $\begin{array}{l}\text { 19. SECURTYYCA } \\
\text { ABSTRACT } \\
\text { Unclassifie }\end{array}$ & ACAIIONOF & $\begin{array}{l}\text { 20. LMTATION OF ABSTRACT } \\
\text { UL }\end{array}$ \\
\hline
\end{tabular}

